\title{
POMDME as an Alternative Pilot Fuel for Dual-Fuel Engines: Optical Study in a RCEM and Application in an Automotive Size Dual-Fuel Diesel Engine
}

Aleš Srna Paul Scherrer Institute

Christophe Barro ETH Zurich

Kai Herrmann FHNW University of Applied Sciences

Fabio Möri, Richard Hutter, and Konstantinos Boulouchos ETH Zurich

Citation: Srna, A., Barro, C., Herrmann, K., Möri, F. et al., "POMDME as an Alternative Pilot Fuel for Dual-Fuel Engines: Optical Study in a RCEM and Application in an Automotive Size Dual-Fuel Diesel Engine," SAE Technical Paper 2018-01-1734, 2018, doi:10.4271/2018-01-1734.

\section{Abstract}

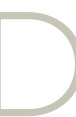

ual-fuel natural gas engines are seen as an attractive solution for simultaneous reduction of pollutant and $\mathrm{CO}_{2}$ emissions while maintaining high engine thermal efficiency. However, engines of this type exhibit a tradeoff between misfire as well as high UHC emissions for small pilot injection amounts and higher emissions of soot and $\mathrm{NO}_{\mathrm{X}}$ for operation strategies with higher pilot fuel proportion. The aim of this study was to investigate POMDME as an alternative pilot fuel having the potential to mitigate the emissions tradeoff, enabling smokeless combustion due to high degree of oxygenation, and being less prone to misfire due to its higher cetane number. Furthermore, POMDME can be synthetized carbon neutrally.

First, characteristics of POMDME ignition in methane/ air mixture and the transition into premixed flame propagation were investigated optically in a rapid compression-expansion machine (RCEM) by employing Schlieren and $\mathrm{OH}^{*}$ chemiluminescence imaging. A single-hole coaxial injector mounted at the cylinder periphery was used to admit POMDME or $\mathrm{n}$-dodecane as the reference pilot fuel. In the second stage, POMDME was applied as a pilot-fuel in a VW 214 -cylinder industrial Diesel engine modified for dual-fuel operation. Engine performance with POMDME and EN590 Diesel pilot-fuels was compared.

In the RCEM, in air, dodecane and POMDME exhibit similar ignition delay times. In methane/air mixtures, ignition of both pilot fuels was deferred with increasing methane content, with stronger influence on POMDME than on dodecane. Indication of pilot-fuel over-mixing was observed for the shortest considered POMDME injections. In the engine experiment, while keeping the total combustion equivalence ratio constant, POMDME was found to have shorter ignition delays than Diesel fuel, attributed to its higher cetane number. At constant engine load using POMDME instead of Diesel pilot fuel, stable operation with lower pilot-fuel energy and mass input was possible along with soot mass reduction to close to zero.

\section{Introduction}

ilot-fuel ignited gas engines have attracted significant attention for their potential of high thermal efficiency, and, in comparison to their Diesel-engines counterpart, considerably reduced soot and $\mathrm{NO}_{\mathrm{x}}$ emissions [1] Furthermore, compressed natural gas (CNG) as main fuel offers the advantage of $30 \%$ lower specific $\mathrm{CO}_{2}$ emissions at comparable or lower market price as the diesel-fuels [2]. Technology conversion of existing Diesel-engines to dual-fuel operation is mechanically relatively straightforward and costeffective, though such engines possibly cannot fully exploit the potential of the dual-fuel technology.

Complying with the present and future engine soot and $\mathrm{NO}_{\mathrm{x}}$ emission legislation by applying the in-cylinder measures only, at Diesel-engine comparable or higher thermal efficiency, could be set as the ultimate goal in the development of dualfuel engines. Under emissions-optimized operational strategy Euro 6 (heavy-duty) compliance of engine-out $\mathrm{NO}_{\mathrm{x}}$ emissions [3] and particulate matter emissions [4] (though exceeding the particulate number limit) has already been demonstrated in a dual-fuel engine at only slightly compromised efficiency (1-2\%). However, several authors observed a tradeoff between low soot and NOx emissions on one hand, and low UHC emissions and high thermal efficiency on the other hand $[\underline{3}, \underline{5}, \underline{6}$, $\underline{7}, \underline{8}, \underline{9}, \underline{10}$ ]. Considering these findings it becomes clear that in order to fulfill the development goals 1.) advanced engine geometry and control systems, based on improved fundamental understanding of the dual-fuel combustion and 
emission formation processes, will be needed and 2.) alternative pilot fuels with improved ignition characteristics and reduced emission formation propensity should be considered.

Fundamental aspects of ignition, flame propagation and sooting propensity of dual-fuel combustion have been investigated experimentally in only a few studies in optical engines $[11, \underline{12}, \underline{13}]$ and RCEMs $[\underline{14}, \underline{15}, \underline{16}, \underline{17}, \underline{18}]$. A strong interaction of methane with pilot-fuel auto-ignition process has been reported leading to considerably prolonged ignition delay of pilot fuel $[\underline{14}, \underline{15}, \underline{16}, \underline{19}, \underline{20}, \underline{21}, \underline{22}]$, possibly resulting in misfire. This ignition delay prolongation is 6-7 times longer than predicted by phenomenological models [23] which account only for the reduced charge oxygen concentration due to methane addition. The ignition process in dual-fuel engines shows a higher complexity than in conventional Diesel engines: besides the chemistry being affected by the methane content of the charge, furthermore, the equivalence ratio and temperature history of fuel parcels are influenced by end-ofinjection-transients and overmixing phenomena, since the injection duration is usually shorter than the ignition delay. During the end of injection transient for short ignition dwell times ignition is accelerated, except in the case of too long ignition dwell when it decelerates due to overmixing $[\underline{24}, \underline{25}$, $\underline{26}, 27]$. Only by a modification of [28] for this methane influence and the end-of-injection transient Barro et al. [27] were able to develop a dual-fuel combustion HRR model with predicting capabilities over a wide range of operating conditions.

Some indication on the source of UHC has been observed in optical engines $[\underline{11}, \underline{12}]$, where the central region of the combustion chamber around injector was found to burn very late in the combustion process. Nithyanandan et al. [12] have shown than multiple pilot injections could accelerate premixed fuel combustion in the middle of combustion chamber. However, at the same time their color images of the combustion process revealed considerably higher thermal luminosity of soot, thus indicating higher sooting propensity of such combustion strategy. Srna et al. [16] optically investigated sooting propensity of dual-fuel combustion a RCEM. While only small influence of methane on formation of soot in the pilot spray has been reported, a considerably deferred oxidation of soot has been observed. Only a small operational window with a positive difference between ignition and end of injection has been identified to have a potential for smokeless operation.

Considering methane deferring the ignition and inhibiting soot oxidation at the same time, the operational window in tradeoff between smokeless combustion and high engine UHC emissions or misfire might not be sufficiently wide to ensure smokeless operation over the whole engine operating map. Low sooting tendency of oxygenated fuels has been demonstrated in both Diesel engines and more fundamental investigations in constant volume chambers for a range of fuels: alcohols (methanol, butanol $[\underline{29}, \underline{30}]$ ), esters (methyldecanoate [31]), ethers (dimethylether, diethylether, POMDMEs $[\underline{32}, \underline{33}, \underline{34}, \underline{35}, \underline{36}, \underline{37}, \underline{38}, \underline{39}])$. Applications of oxygenates as pilot-fuels in dual-fuel engines (Imran with RME in [40] and Song with POMDME in [41]) confirmed the lower sooting tendency also in dual-fuel applications, and with some of the fuels even an extension of the engine operation limits with respect to the ignition was feasible. While some of the oxygenated fuels are not fully compatible with existing Diesel injection technology due to their low lubricity, low boiling point or low cetane number, POMDMEs have similar thermo-fluidic properties as Diesel fuel and even higher cetane number. High level of oxygenation and absence of $\mathrm{C}-\mathrm{C}$ bonds yields fuels of this type very low sooting and thus even smokeless stoichiometric operation of Diesel engines is possible $[\underline{32}, \underline{42}, \underline{43}, \underline{44}]$. As such, high cetane number, comparable adiabatic flame temperatures as Diesel fuel and low sooting tendency indicate high potential of POMDMEs as pilot-fuel for dual-fuel engines. Furthermore, POMDME can be synthesized from methanol and formaldehyde using a power-to-liquid process with a potentially low $\mathrm{CO}_{2}$ footprint [45].

The aim of the present study was 1.) to understand how the specific chemical and thermo-fluidic properties of POMDME influence the dual-fuel applicability of such oxygenated pilot-fuels and 2.) to provide an application example in a dual-fuel converted automotive-size Diesel engine to demonstrate the advantages of POMDME pilot-fuel. The injection and ignition characteristics of POMDME in compressed air and methane/air mixture have been investigated optically in RCEM by means of Schlieren and $\mathrm{OH}^{*}$ chemiluminescence imaging. A comparison to the reference cases with dodecane as the reference pilot-fuel with cetane number comparable to POMDME is presented. With this comparison the influences of the sensitivity of pilot-fuel ignition delay to methane and the sensitivity to the fuel cetane number could be separated. Additionally, $\mathrm{n}$-dodecane is well characterized fuel with detailed chemical kinetics available, thus adding the value of the RCEM tests as the reference cases for validation of CFD calculations. In the engine application the research was focused on the engine-out soot emissions and the minimal required pilot-fuel quantity to ensure stable combustion. The importance of the pilot-fuel cetane number and methane sensitivity has been highlighted. Intermediate loads (5-8 bar BMEP) and high global equivalence ratio $(\phi=0.75-1)$ have been considered.

The publication is structured as follows: in the next section the RCEM and dual-fuel engine test rig, operating conditions and the diagnostic approach are introduced. In the results section first the fundamental aspects of POMDME pilot spray ignition in methane/air mixtures in the RCEM are presented, followed by an application example of POMDME in a dual-fuel engine. The discussion corroborates both sets of experimental results towards the conclusions on the POMDME performance as an alternative pilot-fuel for leanburn and stoichiometric dual-fuel engines.

\section{Experimental Setup}

\section{Pilot Fuels}

Two different mixtures of POMDMEn's with different chain length (2-4 and 3-4) have been used. Chemical formula of such oxygenated fuels is $\mathrm{CH}_{3}-\mathrm{O}-\left(\mathrm{CH}_{2}-\mathrm{O}\right)_{\mathrm{n}}-\mathrm{CH}_{3}$ and the acronym POMDME $\mathrm{n}_{\mathrm{n}}$ (also known as OME, PODE) stands for Poly-oximethyl-dimethyl-ether with chain length of n. For 
the more fundamental investigation in the RCEM, n-dodecane has been selected as reference fuel with comparable boiling point, viscosity and cetane number, to ensure similar spray penetration and ignition delay in air for both fuels. Therefore it was possible to compare methane influence on ignition of POMDMEand dodecaneas a typical hydrocarbon representative.

In the Diesel engine, the aim was to simulate a more realistic situation where POMDME would replace a presently used pilot fuel. Therefore the engine was operated with POMDME and standard EN590 Diesel as pilot fuels. Operation with n-dodecane for the comparison would be prohibitive from the fuel-cost perspective. An overview of the employed pilot fuels characteristics is presented in Table 1.

POMDME and n-dodecane have similar properties except for considerably different LHV and stoichiometric air-fuel ratio. Furthermore, POMDME has approximately $30 \%$ higher density than $\mathrm{n}$-dodecane. In comparison to Diesel fuel, both POMDME and n-dodecane have a significantly higher cetane number. Therefore, a considerably different ignition behavior of POMDME can be expected comparing to Diesel fuel. Nevertheless, the influence of methane on the ignition delay is expected to play a major role as well. The differences between the two used POMDMEs are very small in comparison to Diesel or dodecane regarding the combustion relevant characteristics like oxygen content, cetane number, stoichiometric AFR, LHV and density (Table 1).

\section{Rapid Compression-Expansion Machine (RCEM)}

The fundamental characteristics of POMDME ignition in compressed methane/air charge have been investigated by application of Schlieren and $\mathrm{OH}^{*}$ chemiluminescence optical

TABLE 1 Main characteristics of the pilot fuels considered in the study.

\begin{tabular}{|c|c|c|c|c|}
\hline $\begin{array}{l}\text { Experimental } \\
\text { Carrier }\end{array}$ & RCEM & & Engine & \\
\hline Pilot fuel & $\begin{array}{l}\text { POMDME } \\
n_{3,4}\end{array}$ & n-dodecane & $\begin{array}{l}\text { POMDME } \\
\mathrm{n}_{2-4}\end{array}$ & $\begin{array}{l}\text { EN590 } \\
\text { Diesel }\end{array}$ \\
\hline $\begin{array}{l}\text { Density@25 }{ }^{\circ} \mathrm{C} \\
{\left[\mathrm{kg} / \mathrm{m}^{3}\right]}\end{array}$ & 1040 & 750 & 1017 & 840 \\
\hline $\begin{array}{l}\text { Viscosity@25 ㄷ } \\
{[\mathrm{Pa} \mathrm{s}]}\end{array}$ & 0.95 & 1.34 & $0.8-0.9$ & 2.5 \\
\hline Boiling point $\left[{ }^{\circ} \mathrm{C}\right]$ & 192 & 216.2 & $\sim 150$ & $\begin{array}{l}170- \\
390\end{array}$ \\
\hline $\begin{array}{l}\text { Cetane number } \\
{[-]}\end{array}$ & $70-80$ & 73 & $70-80$ & 52 \\
\hline LHV [MJ/kg] & 19.4 & 44.1 & $\sim 20$ & 42.1 \\
\hline $\begin{array}{l}\text { Oxygen content } \\
\text { [wt. \%] }\end{array}$ & 47.9 & 0 & $\sim 46$ & 0 \\
\hline $\begin{array}{l}\text { Stoichiometric } \\
\text { air-fuel ratio } \\
{[\mathrm{kg} / \mathrm{kg}]}\end{array}$ & $\sim 6.1$ & 15.0 & $\sim 6.2$ & $\sim 15.6$ \\
\hline Composition & $\begin{array}{l}n_{3} 80 \% \\
n_{4} 20 \%\end{array}$ & $\begin{array}{l}\text { n-dodecane } \\
\text { 99.3\% pure }\end{array}$ & $\begin{array}{l}\mathrm{n}_{2} 33.5 \% \\
\mathrm{n}_{3} 38.5 \% \\
\mathrm{n}_{4} 28 \%\end{array}$ & - \\
\hline
\end{tabular}

(c) 2018 SAE International. All Rights Reserved. techniques in a Rapid Compression Expansion Machine (RCEM). The employed RCEM is a generic free-floating piston test rig (bore: $84 \mathrm{~mm}$, variable stroke: $120-249 \mathrm{~mm}$ ) with optical accessibility through piston and cylinder head windows. A brief description of the machine and its operation principle is provided here, while more detailed descriptions are available in $[\underline{14}, \underline{46}, \underline{47}]$.

A sectional view of the RCEM and its operating principle is presented in Figure 1. The machine operates in a single stroke mode (compression and partial expansion). The drive energy for the piston motion is provided through the compressed air charge acting on a system of hydraulically coupled working piston and mass-balance piston, which move in the opposite directions to enable vibration free operation. Due to the absence of mechanical piston coupling to a flywheel, the piston acceleration is governed by the pressure difference between driving volume and combustion chamber. The subsequent piston motion results in a pendulum-like swing with a fast ejection of the piston towards the top dead center (TDC). The piston decelerates as the pressure in the combustion chamber builds up and swings back towards the equilibrium position.

The RCEM combustion chamber has a cylindrical geometry with a flat cylinder head and virtually flat piston (2.2 mm piston bowl) (Figure 2). A standard common-rail Diesel injector body (Bosch CRI2-16) equipped with a custom $100 \mu \mathrm{m}$ diameter single-hole conical coaxial nozzle tip (KS 1.5 , discharge coefficient $C_{d}=0.80$ ) has been used to admit the pilot fuel. The pilot injector was mounted on the cylinder periphery at $5^{\circ}$ axis inclination towards piston. The nozzle orifice position was located at a distance of $5 \mathrm{~mm}$ from the cylinder head and $42.5 \mathrm{~mm}$ from the cylinder axis.

The boundary conditions in this RCEM experimental configuration have been investigated in previous studies, therefore not repeated here. High homogeneity of the BDC temperature distribution [14] and methane mixing quality [16] have been reported. PIV investigations [47] showed that flow conditions in the RCEM remain quiescent throughout the compression stroke.

FIGURE 1 Sectional view of the RCEM and schematic of the operation principle of the oil-coupled free-floating working and balancing piston. Adapted from [47].

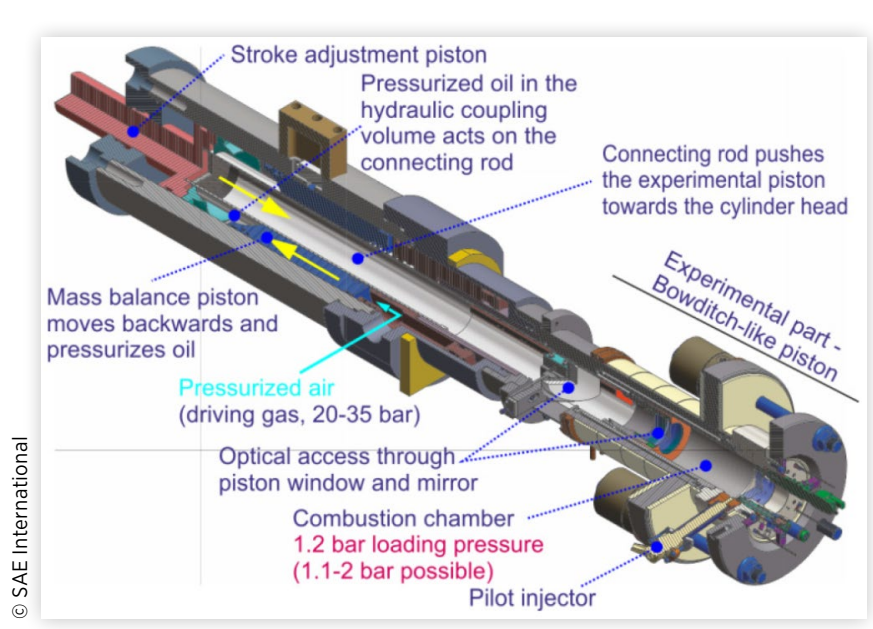


FIGURE 2 RCEM combustion chamber geometry. Dimensions in $\mathrm{mm}$.

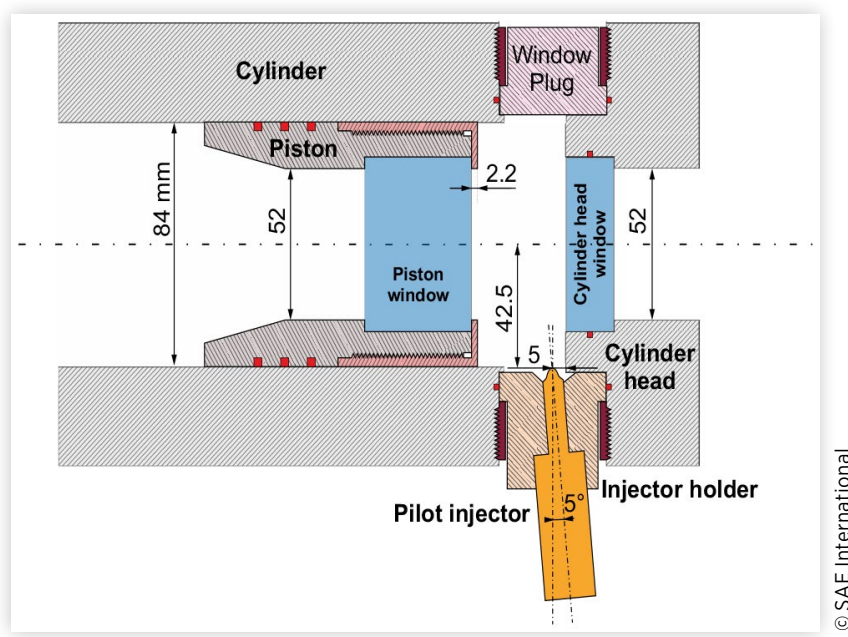

The RCEM instrumentation includes precise recording of the piston position (resolution $0.02 \mathrm{~mm}$ ) and cylinder pressure (flush-mounted piezoelectric transducer, Kistler $7061 \mathrm{~B}, 0-250 \mathrm{bar}$ ) at rate of $100 \mathrm{kHz}$. The piezoelectric sensor is pegged using a precise absolute pressure transducer (Kistler 4075A10, 0-10 bar) in a fast-switching adapter (Kistler 741A). General RCEM specifications are given in Table 2.

Operating Conditions In this study the RCEM has been operated at the maximal BDC displacement setting $\left(1.38 \mathrm{dm}^{3}\right.$ displacement, $249 \mathrm{~mm}$ BDC clearance to the cylinder head) to have a sufficient TDC clearance for minimizing the pilot spray interaction with walls.

The operation strategy with high compression ratio $(\mathrm{CR}=20)$ and early pilot injection (SOI at $3.5 \mathrm{~ms}$ before TDC) has been selected to ensure high repeatability of the conditions at SOI, based on the experience gained in previous studies [16]. The resulting piston motion over the time interval [ $-4 \mathrm{~ms}, 4 \mathrm{~ms}]$ around the TDC can be characterized by the

TABLE 2 General specifications of the RCEM.

\begin{tabular}{|l|l|}
\hline Cylinder bore & $\mathbf{8 4} \mathbf{~ m m}$ \\
\hline Stroke & Adjustable, 120-249 mm \\
\hline Displaced volume & $0.67-1.38 \mathrm{dm}^{3}$ \\
\hline Realizable compression ratio & $5-25$ \\
\hline Charge intake pressure & $1.1-2 \mathrm{bar}$ \\
\hline Cylinder head geometry & flat \\
\hline Piston bowl geometry & Top hat, Ø52 $\mathrm{mm} \times 2.2 \mathrm{~mm}$ \\
\hline Cylinder liner and head heating & Multi-zone electric, up to $450 \mathrm{~K}$ \\
\hline Optical access & $\begin{array}{l}\text { Piston window, Ø52 mm } \\
\text { Cylinder head window } \varnothing 52 \mathrm{~mm} \\
\text { Lateral window Ø36 mm (not } \\
\text { used) }\end{array}$ \\
\hline Pilot fuel injection & $\begin{array}{l}\text { Bosch CRI2-16 injector body } \\
\varnothing 100 \mu \mathrm{m} \text { KS1.5 single hole } \\
\text { coaxial nozzle }\end{array}$ \\
\hline Methane injector & $\begin{array}{l}\text { Continental outwards opening } \\
\text { hollow-cone nozzle }\end{array}$ \\
\hline
\end{tabular}

piston motion of an engine running at 1200RPM with the same stroke (connecting rod ratio 1.64) as the RCEM.

The bulk temperature during compression has been estimated using a thermodynamic model accounting for compression, wall heat losses, crevice volumes and piston rings blow-by. At cylinder wall temperature of $363 \mathrm{~K}$ the temperature at the start of injection $\left(\mathrm{T}_{\mathrm{SOI}}\right)$ was reckoned at $810 \mathrm{~K}$. Pressure at the SOI was 25 bar. An overview of the investigated conditions is presented in Table 3.

Combustion chamber charge consisted of air $\left(21 \% \mathrm{O}_{2}\right)$ mixed with methane. The $\mathrm{T}_{\mathrm{SOI}}$ change due to the high methane specific heat ratio was estimated to be $6 \mathrm{~K}$ for the highest considered methane concentration - neglected consequently in the further analysis.

Three injection durations (300, 400 and $500 \mu$ sT) were considered for $n$-dodecane, resulting in a factor 3 difference in the injected mass. The lower ET was limited by the stability limit of the pilot- injector operation. A part of this data was published in earlier works [16]. The same injection durations were considered also for POMDME. Additionally a longer $\mathrm{ET}=700 \mu$ s injection was included to compensate for the lower LHV of POMDME. (POMDME 400 and $700 \mu \mathrm{s}$ ET injections have comparable energy input as 300 and $400 \mu \mathrm{s}$ ET n-dodecane injections, respectively).

The injection rate profile of the pilot injector has been characterized for the selected rail pressures and energizing times using a "Bosch tube" type injection rate analyzer using $n$-dodecane as the hydraulic liquid. The measured steady fuel injection rate at 30 bar tube pressure was $2.43 \mathrm{mg} / \mathrm{ms}$ at

TABLE 3 Overview of the operating conditions for POMDME (middle column) and dodecane (right column) pilot fuels.

\begin{tabular}{|c|c|c|}
\hline & $\begin{array}{l}\text { Dataset 1: } \\
\text { POMDME }\end{array}$ & $\begin{array}{l}\text { Dataset 2: } \\
\text { n-dodecane }\end{array}$ \\
\hline BDC displacement & \multicolumn{2}{|l|}{$1.38 \mathrm{dm}^{3}$} \\
\hline $\begin{array}{l}\text { Charge intake } \\
\text { pressure }\end{array}$ & \multicolumn{2}{|l|}{1.2 bar } \\
\hline Stroke & \multicolumn{2}{|l|}{$236.5 \mathrm{~mm} \pm 1 \mathrm{~mm}$} \\
\hline Compression ratio & \multicolumn{2}{|l|}{20} \\
\hline BDC temperature & \multicolumn{2}{|l|}{$363 \mathrm{~K}$} \\
\hline $\begin{array}{l}\text { Pressure at SOI } \\
\left(P_{\text {sol }}\right)\end{array}$ & \multicolumn{2}{|l|}{25 bar } \\
\hline $\begin{array}{l}\text { Temperature at SOI } \\
\left(\mathrm{T}_{\mathrm{SOI}}\right)\end{array}$ & \multicolumn{2}{|l|}{$810 \mathrm{~K}$} \\
\hline Pilot fuel & POMDME $\mathbf{n}_{3,4}$ & n-dodecane \\
\hline $\begin{array}{l}\text { Pilot injector } \\
\text { energizing time (ET) }\end{array}$ & $\begin{array}{l}300 \mu \mathrm{s}, 400 \mu \mathrm{s} \\
500 \mu \mathrm{s}, 700 \mu \mathrm{s}\end{array}$ & $\begin{array}{l}300 \mu \mathrm{s}, 400 \mu \mathrm{s}, \\
500 \mu \mathrm{s}\end{array}$ \\
\hline $\begin{array}{l}\text { Pilot injection } \\
\text { duration }\end{array}$ & $\begin{array}{l}0.40 \mathrm{~ms}, 0.58 \mathrm{~ms} \\
0.77 \mathrm{~ms}, 1.34 \mathrm{~ms}\end{array}$ & $\begin{array}{l}0.40 \mathrm{~ms}, 0.58 \mathrm{~ms} \text {, } \\
0.77 \mathrm{~ms}\end{array}$ \\
\hline $\begin{array}{l}\text { Pilot fuel mass per } \\
\text { injection }\end{array}$ & $\begin{array}{l}0.68 \mathrm{mg}, 1.42 \mathrm{mg} \\
2.13 \mathrm{mg}, 2.81 \mathrm{mg}\end{array}$ & $\begin{array}{l}0.58 \mathrm{mg}, 1.21 \mathrm{mg} \\
1.81 \mathrm{mg}\end{array}$ \\
\hline $\begin{array}{l}\text { Pilot fuel LHV per } \\
\text { injection }\end{array}$ & $14 \mathrm{~J}, 28 \mathrm{~J}, 43 \mathrm{~J}, 56 \mathrm{~J}$ & $26 \mathrm{~J}, 53 \mathrm{~J}, 80 \mathrm{~J}$ \\
\hline $\begin{array}{l}\text { Pilot injection } \\
\text { pressure }\end{array}$ & 600 bar & \\
\hline $\begin{array}{l}\text { Methane/air mixture } \\
\text { equivalence ratio } \\
\left(\varphi_{\mathrm{CH} 4}\right)\end{array}$ & $0,0.33,0.48,0.59$ & \\
\hline
\end{tabular}


600 bar rail pressure and the duration of the injector opening and closing transient was $140 \mu \mathrm{s}$. By considering similar hydraulic properties of $n$-dodecane and POMDME the same volumetric injection rate and transient behavior has been assumed for both fuels. Under this assumption approximately $15 \%$ higher mass of POMDME is injected for the same injection duration.

\section{Schlieren and $\mathrm{OH}^{*}$ Chemiluminescence} Imaging To detect the pilot spray penetration, ignition delay and flame spreading, a setup using simultaneous Schlieren and $\mathrm{OH}^{*}$ imaging has been applied at the RCEM (Figure 3). The same optical setup has been already employed in previous studies [16]. Both optical methods were applied along the same optical axis through the $\varnothing 52 \mathrm{~mm}$ piston and cylinder head windows (Figure 2). All devices were synchronized using a programmable timing unit (LaVision).

Imaging along the same optical axes was possible due to the fact that Schlieren imaging and $\mathrm{OH}^{*}$ use considerably different spectral ranges. $\mathrm{OH}^{*}$ detection is performed around $310 \mathrm{~nm}$ while a red light source was used for Schlieren imaging (690 nm, as described below). By using a long-pass dichroic mirror the required wavelengths could be separated and directed towards the corresponding detector.

Schlieren imaging has been performed at frame rate of $80 \mathrm{kHz}$ with a projected pixel size of $0.16 \mathrm{~mm} /$ pixel. A fibercoupled pulsed laser diode array (Cavilux Smart, wavelength $690 \pm 10 \mathrm{~nm}, 10 \mathrm{~ns}$ pulse duration, $440 \mathrm{~W}$ output) illuminating a close-coupled diffusor plate and a $1 \mathrm{~mm}$ diameter pinhole has been used to generate a point light source. The light has been collimated using a $100 \mathrm{~mm}$ diameter $\mathrm{f} / 4$ achromatic lens and directed along the cylinder axis through the combustion chamber. The collimated beam has been then refocused using another achromatic lens of the same type. An aperture diameter of $3 \mathrm{~mm}$ in the lens focal point has been used as Schlieren stop. After passing the Schlieren stop the light was recorded with a high-speed camera (Photron Fastcam SA-X2) equipped with a Nikkor $50 \mathrm{~mm}$ f/1.4 lens to achieve the desired image scale. Camera exposure time was $1 \mu \mathrm{s}$; the lens was equipped with a $690 \mathrm{~nm}$ bandpass filter to suppress the flame luminosity. The aperture sizes of $1 \mathrm{~mm}$ and $3 \mathrm{~mm}$ were selected to achieve a sufficient contrast of the Schlieren images by an empirical approach, as described in [48], resulting in similar beam-divergence tolerance of the system as in other comparable studies [15, $\underline{49}]$. Due to hardware obstructions

\section{FIGURE 3 Optical setup for simultaneous Schlieren and} $\mathrm{OH}^{*}$ chemiluminescence imaging.

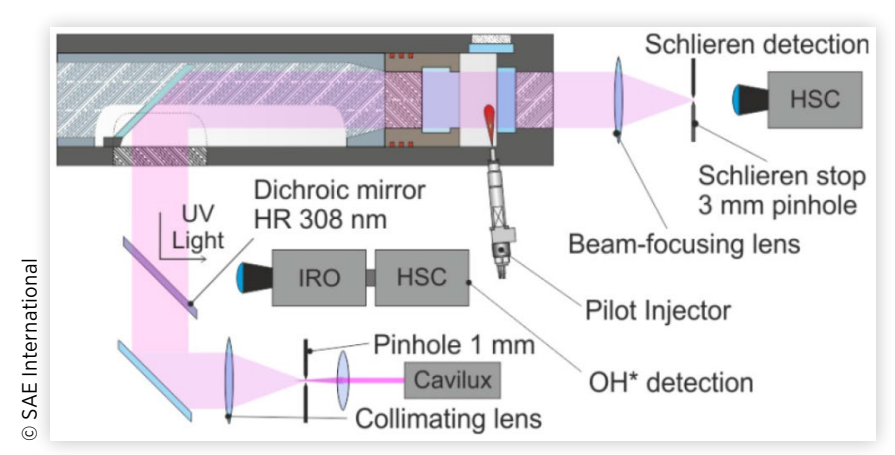

(c) 2018 SAE International. All Rights Reserved. between the piston and mirror the region closer than $22 \mathrm{~mm}$ to the injector orifice is not visibly accessible.

Filtered flame emission in the spectral range of chemically excited hydroxyl $\left(\mathrm{OH}^{*}\right.$ radicals) has been acquired at a frame rate of $40 \mathrm{kHz}$ using an image intensifier (LaVision HS-IRO, S20 photocathode), relay-optics coupled to a highspeed camera (Photron FastCam SA1.1). The intensifier was equipped with a Sodern UV lens (Cerco $100 \mathrm{~mm} \mathrm{f} / 2.8$ ) and a bandpass filter $(313 \mathrm{~nm} \pm 13 \mathrm{~nm}$ ). The resulting resolution was $0.18 \mathrm{~mm} / \mathrm{pixel}$. The intensifier gate was set to $20 \mu \mathrm{s}$ and the gain was adapted to the brightness of the flame emission under different conditions (9-45 counts/photoelectron for n-dodecane pilot, 18-133 counts/photoelectron for POMDME cases). The UV radiation has been separated from the Schlieren beam using a $308 \mathrm{~nm} 45^{\circ}$ dichroic laser mirror $(100 \mathrm{~mm}$ diameter, $95 \%$ reflection in range $295-325 \mathrm{~nm}, 87 \%$ transmission at $690 \mathrm{~nm}$ ).

\section{Dual-Fuel VW 2 L 4-Cylinder Industrial Diesel Engine}

All engine experimental investigations of this study were carried out on a modified production-type Diesel engine as already used in $[\underline{50}, \underline{51}, \underline{52}]$. The compressed natural gas (CNG) is injected in the air intake port during the intake stroke. The pilot fuel (Diesel or POMDME, $\mathrm{n}_{2-4}$ ) is injected directly into the cylinders with a common rail system. After the turbine an oxidation catalyst and a Diesel particulate filter (DPF) are mounted, and low pressure EGR path with an EGR cooler is added to the system. A bypass of the high pressure EGR path allows heating of the intake air. The major modification to the engine consists of the fitting of the CNG injectors. These injectors are mounted in a plastic plate which is located between the intake manifold and the cylinder head. Bosch NGI2 CNG injectors are fitted in one of the intake ports. Swirl valves are situated in the other of the two intake ports per cylinder and can be fully closed. A current clamp is used to measure the current signal of the pilot fuel injector from cylinder \#1 to analyze the start of injection (SOI) with high precision. This signal and the pressure signals of cylinders $\# 1, \# 2$ and $\# 4$ are recorded as well. The experiments are conducted using a $\lambda$ and a load controller. Lambda sensors, which are mounted after the cylinder \#1, cylinder \#4 and after the turbine, allow online control of the global equivalence ratio by adapting the CNG quantity injected in the cylinders. The load is adapted with the VTG turbine and the throttle. Start of injection (SOI) and duration of injection (DOI) of the pilot fuel are predefined and constant during the measurement at each operating condition. The consumption of pilot fuel is measured with a reservoir on a scale and the consumption of CNG is measured by a Rheonik RHM 015 Coriolis mass flowmeter. Exhaust gases are sampled after the turbine and before the DPF. An AVL Micro Soot Sensor is used to detect the particulate matter and Cambustion DMS 500 particle sizer measured the particle number. The latter provides a spectral distribution of the particles in a resolution of 22 different sizes. The device contains two dilution systems in series without any additional volatile particle remover. As a consequence, if particles are present in nucleation (diameter smaller than primary particle 
size) and agglomeration mode (particles larger than primary particle size), the primary particle size can be estimated and the nucleation mode particles are assumed to be volatile or non-organic. The formation of volatile particles can be promoted by high dilution.

Table 4 provides the engine characteristics.

Operating Conditions The experimental matrix consists of three variations: global equivalence ratio variation at different loads (OP1 - OP3), a sweep in pilot fuel quantity (OP4) and a set of operating conditions with a high soot formation potential (OP5 - OP8, using high EGR rates and large pilot fuel quantities) (Table 5). Each of the operating conditions was performed both with POMDME pilot fuel as well as standard Diesel pilot fuel for reference. In OP1 and OP4, at low load (BMEP 5 bar) and minimum pilot fuel quantities, longer injection duration with Diesel fuel was necessary to achieve stable operation.

Engine was operated with the pilot fuel pressure set to 500 bar for all measurements. The intake manifold temperature was kept constant at around $305 \mathrm{~K}$ for all cases.

TABLE 4 Characteristics of base Diesel engine.

\begin{tabular}{|c|c|c|}
\hline \multicolumn{3}{|c|}{ VW TDI 2.0-475 NE/CJDA } \\
\hline Displacement & $\mathrm{cm}^{3}$ & 1968 \\
\hline Number of Cylinders & - & 4 \\
\hline Bore/Stroke & $\mathrm{mm}$ & $81 / 95.5$ \\
\hline Compression Ratio & - & 16.5 \\
\hline
\end{tabular}

TABLE 5 Engine operating condition overview.

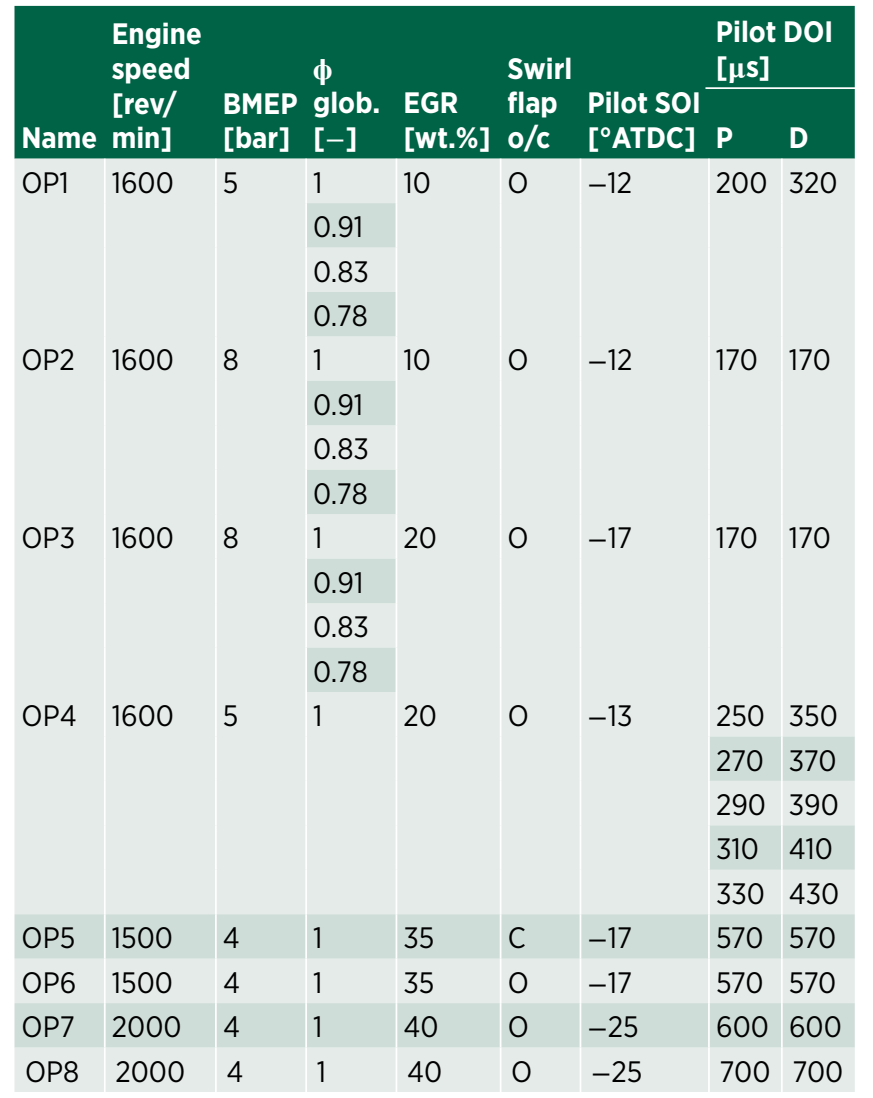

\section{RCEM Results and Discussion}

The aim of the RCEM investigations was to provide the fundamental information on the POMDME injection and combustion behavior. Spray penetration was investigated to provide information on the mixing state of the spray at ignition. In the next stage the ignition and HRR characteristics of POMDME were compared to a $\mathrm{HC}$ fuel with comparable cetane number.

\section{Spray Penetration and Mixing}

Both POMDME and dodecane pilot fuels have a similar viscosity and boiling point thus making it reasonable to expect similar nozzle area contraction coefficient values during the injection. Under this assumption and at same injection pressure, POMDME injection will have same momentum flux as dodecane but approximately $15 \%$ lower injection velocity.

Schlieren imaging has been employed to detect the spray penetration of both POMDME and dodecane injections in order to investigate the spray behavior of both fuels. Images were processed using the adaptive background subtraction methodology proposed by the Engine Combustion network [53]. The processing begins with the first acquired image serving as the background, subtracted from the succeeding image. After background subtraction the spray/flame regions appear bright, and are separated from environment based on a thresholding approach. The process continues with assuming the regions without the spray detected as the new background, whereas the previous background is assumed for the regions with spray detected. This adapted background is then subtracted from the next image. The threshold was selected in a trial-and-fail procedure until the methodology reliably detected the spray-contour. Spray penetration has been derived from the contours and averaged over 10 repetitions of the experiment. Figure 4 compares spray penetration of both pilot fuels for a variation of injection duration.

FIGURE 4 Temporal evolution of POMDME (full line) and $n$-dodecane (dashed) pilot-fuel spray tip penetration in air for variation of injector ET.

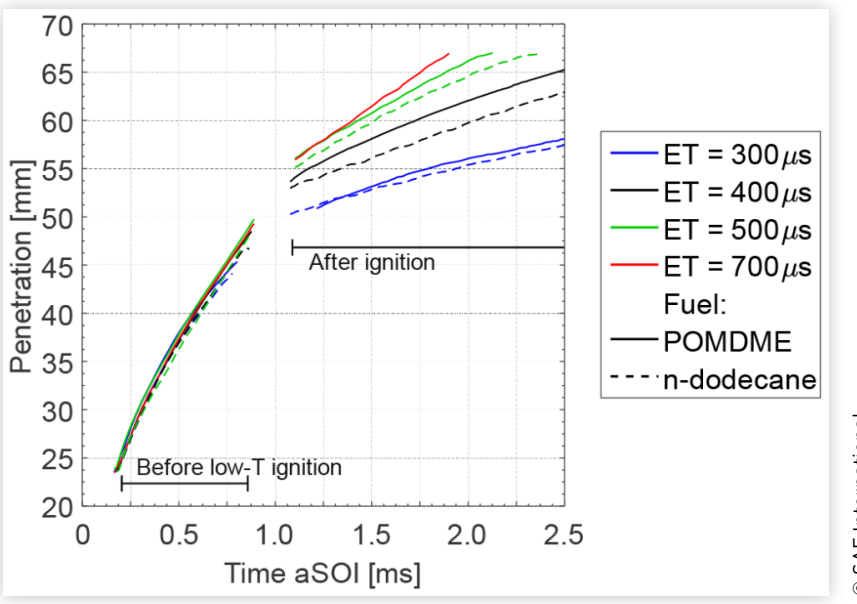

(c) 2018 SAE International. All Rights Reserved. 
Two regions can be distinguished in the pilot-spray penetration curves, separated by a time interval when low-T combustion is progressing. The heat released during this time causes so called softening of the Schlieren contours [48] resulting in unreliable detection of the spray penetration during this period - therefore penetration in this interval is not plotted.

Before the low-T ignition no difference between injections with different energizing times has been observed. First indication of slower penetration for the $\mathrm{ET}=300 \mu \mathrm{s}$ injection is visible at around $0.75 \mathrm{~ms}$ just prior to the low-T ignition. This corresponds well to the twice the injection duration time (0.40 ms x 2$)$ as predicted by the momentum based spray models due to the entrainment wave [54]. It is interesting to note that during the first phase no difference in spray penetration between both employed fuels has been observed. Also comparison of spray cone angles did not show any measurable difference. Considering only small influence of fuel density on spray penetration [55] such result was expected and it confirms that same mixing distribution for both fuels can be assumed. This finding is important for the later analysis of the reactive cases since it offers a comparison of the fuel reactivity at same mixing state.

After ignition larger differences in the penetration of different injections have been observed. The difference between the injections with different duration can be attributed to momentum dissipation due to the entrainment wave [54] after the end of injection. Between injections of dodecane and POMDME generally further penetration has been observed with POMDME. This can be attributed to different stoichiometric air-fuel ratio and LHV between both fuels, resulting in a difference in burnt-gas expansion during the spray combustion.

\section{Ignition Delay}

Ignition delays of pilot-fuel in air and in methane-air mixtures with various methane equivalence ratios have been determined using well established $\mathrm{OH}^{*}$ chemiluminescence imaging. Detection of ignition was defined with an image processing procedure as in previous studies [16]: when the light intensity of $\mathrm{OH}^{*}$ exceeds a threshold of $1 \%$ of the camera dynamic range in area larger than 60 pixel $^{2}$, ignition has occurred. This threshold relates to the lowest intensifier gain for n-dodecane and POMDME, and was increased along with the gain for other cases. The sensitivity of ignition delay on the threshold was assessed by varying the threshold from $0.5 \%$ to $2 \%$, which resulted in less than one image frame change of the detected ignition delay $(25 \mu \mathrm{s})$. Using even lower thresholds was not possible due to the camera noise.

Figure 5 compares the POMDME and n-dodecane ignition delay over a range of methane/air equivalence ratios. Additionally, Figure 6 presents the dependence of ignition delay on the injection duration, both in air and in methane/ air mixture. Ignition delay was stable for all investigated conditions with maximal standard deviation of the ignition delay of about 5\%. In air, both POMDME and n-dodecane have very similar ignition delays. A trend of shorter ET injection having slightly shorter ignition delay $(100 \mu$ s difference) has been observed for both fuels (Figure 6). The trend was
FIGURE 5 Dependence of POMDME (crosses, full line) and $n$-dodecane (circles, dashed) ignition delay on methane equivalence ratio for a variation of injector ET. The lines are data interconnectors and aim at aiding the reader to orient on the plot.

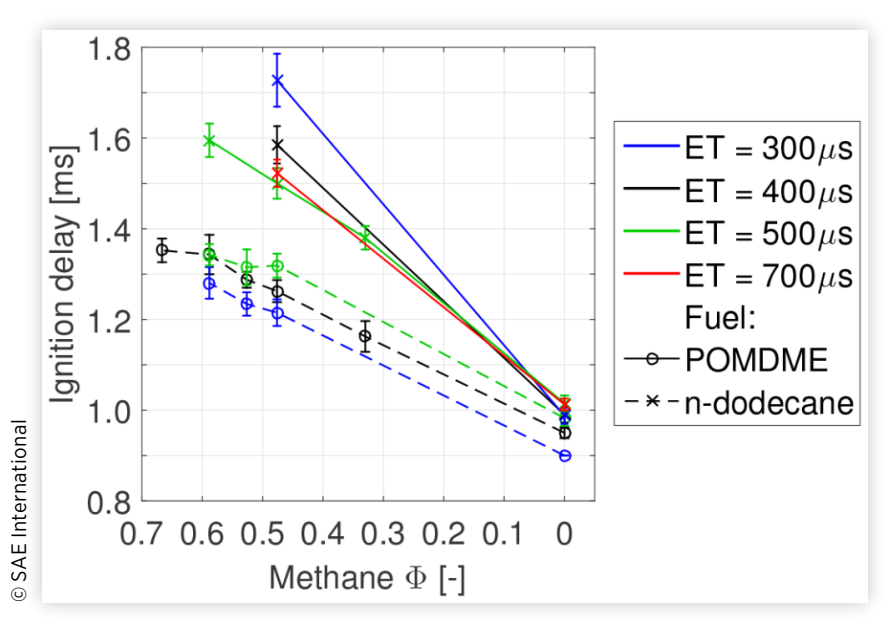

FIGURE 6 Dependence of POMDME (crosses, full line) and $\mathrm{n}$-dodecane (circles, dashed) ignition delay on injection duration in air (a) and in methane/air $\phi_{\mathrm{CH} 4}=0.48$ mixture (b).

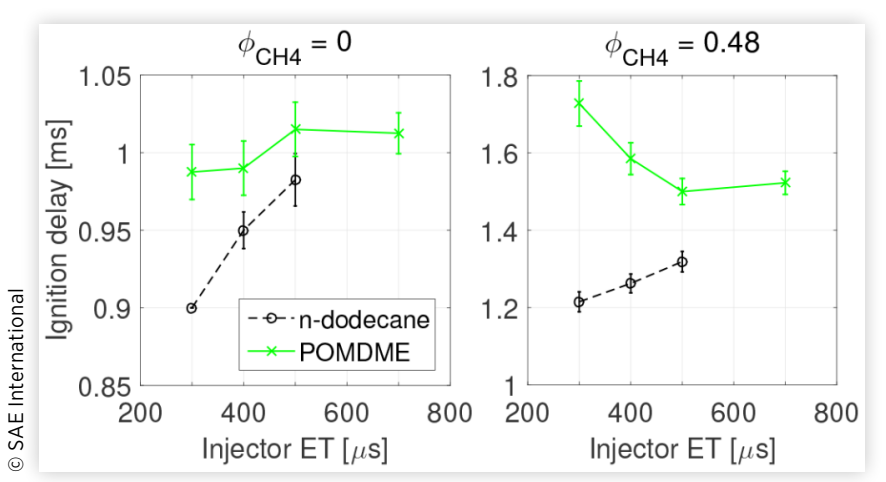

more pronounced with dodecane. These differences observed here are not significant. Nevertheless, this influence might be more pronounced under other conditions ( $40 \%$ decrease reported in [22]).

In methane/air mixtures a considerable prolongation of the pilot-fuel ignition delay has been observed (Figure 5), with the influence increasing with methane concentration. This behavior has been reported for various pilot fuels [15, 17]. For $\mathrm{n}$-dodecane this has been previously reported by the authors [16]. In comparison to dodecane POMDME was found to have more than $70 \%$ higher sensitivity of the ignition delay to methane. Furthermore, the sensitivity of POMDME to methane was even amplified in case of short ET injections (Figure 6). In contrary, n-dodecane did not exhibit such dependence to injection duration. Considering also higher fluctuations of the ignition delay of short POMDME injections in methane (factor 2 increase), it was concluded that pilot-fuel lean-out was the cause of this additional sensitivity.

The observed difference in the fuels sensitivity to methane is highly significant. It shows that when an alternative pilot fuel is used in methane containing charge, models predicting 
ignition delay need to account both for cetane number as well as for the fuel-specific sensitivity to methane. Furthermore, close to lean-out this has a strong influence on the HRR (section Heat Release Rate). The significance of this information is further elaborated with a pilot-fuel ignition model below.

Figure 7 shows a schematic view of the ignition delay in dual-fuel engines from [27]. This model attempts to summarize the chemical influence of methane, the end-of-injection transient shortening the ignition delay (Figure 6) and the overleaning prolonging the ignition. The model assumes substitution of Diesel-fuel by increasing $\phi_{\mathrm{CH} 4}$ and reducing the diesel injection duration. The horizontal axis indicates the fuel share, the vertical axis shows the time of ignition delay (ID) and injection duration (DOI). The dash-dotted line indicates a reference ignition delay without substrate fuel dilution, without end-ofinjection transient and without overmixing at a reference temperature and density. The line with angle $\beta$ indicates the sensitivity of the pilot-fuel ignition delay to substrate fuel equivalence ratio. The line with angle $\alpha$ represents the injection rate. Crossing this line vertically with the applied pilot fuel mass provides the duration of injection on the vertical axis. If the line with the injection rate crosses the line with angle $\beta$, the duration of injection exceeds the ignition delay and no end of injection transient occurs. The figure shows two sample injection rates (1 in blue, 2 in red). The higher injection rate case (1, blue, lower inclination) falls in the overmixing regime (overproportional increase of the ignition delay) while the ignition delay of the longer injection is accelerated by the end of injection transient [27]. The shape of the end-of-injection, resp. overmixing curve is depending on pilot fuel stoichiometric AFR and on the substrate equivalence ratio.

Figure 8 shows a similar schematic view as Figure 7, adapted for two different pilot-fuel and substrate-fuel combinations, indicated with the two different angles $\beta$. This angle is representative for the changing chemistry, depending on the pilot fuel substitution rate. Figure 5 indicates that the investigated fuel combinations have a different dependency of the ignition delay on the pilot fuel share, respectively on the substrate fuel equivalence ratio. This schematic view provides an explanation for the larger spread of ignition delay with different durations of injection using POMDME as pilot fuel.

FIGURE 7 Schematic view of ignition delay in dual fuel engines, adapted from [27].

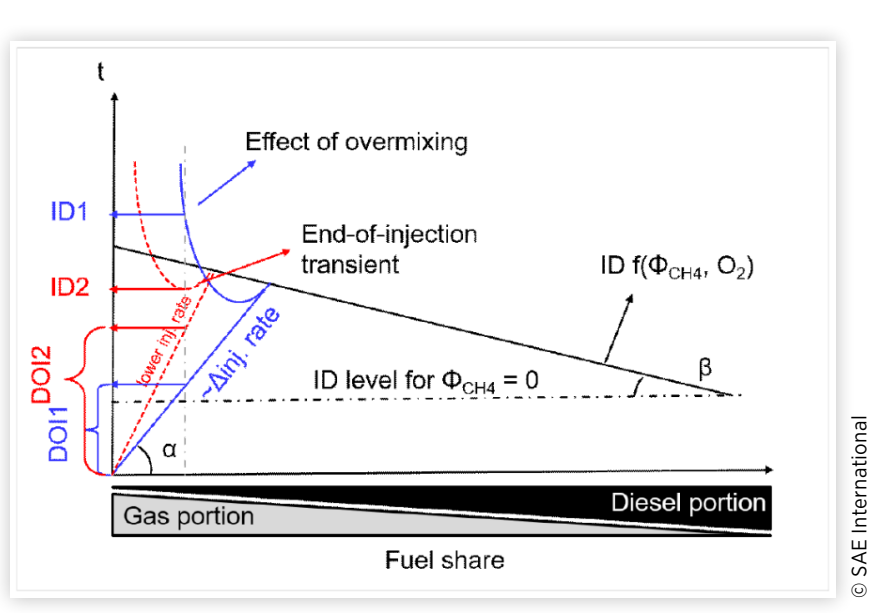

FIGURE 8 Schematic view of ignition delay in dual fuel engines; adapted for two different pilot fuels.

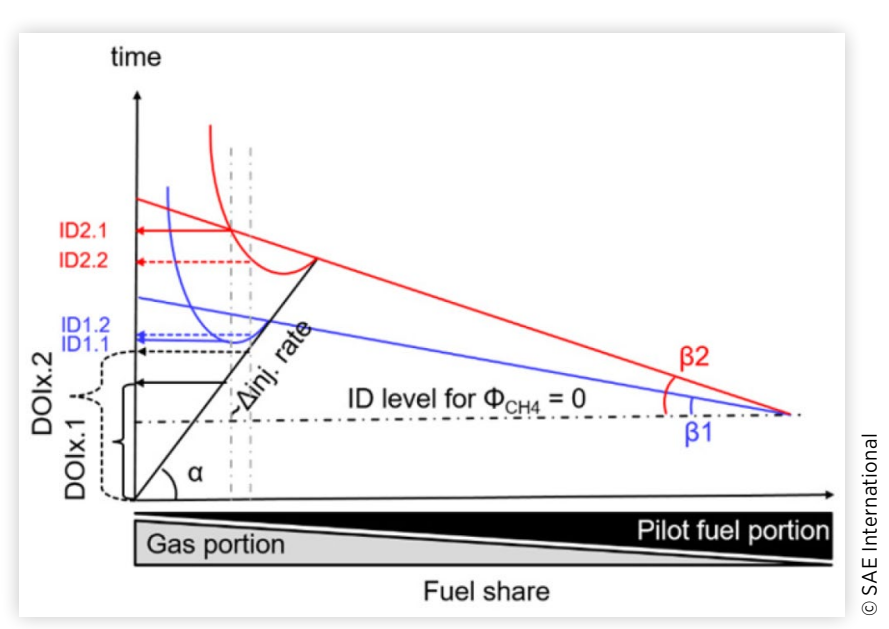

The blue color represent dodecane, the red POMDME. The vertical axes indicates two different durations of injections (DOI x.1 and DOI x.2), which are equal for the two fuels and the according ignition delays (ID1.1 \& ID1.2 for dodecane and ID2.1 \& ID2.2 for POMDME, with the indices according to the injection duration). For a pilot fuel with lower methane sensitivity (lower angle $\beta$, blue case) the end-of-injection-effects are less pronounced at the same pilot-fuel quantity than for a more sensitive fuel (red case), attributed to the lower separation of ignition and end of injection. The resulting difference in ignition delay for the two different injection durations is smaller and negative for the blue case in comparison to the red under similar end-of-injection behavior. The significance of this is that the maximal feasible gas-portion depends not only on the fuel cetane number (ID level for $\phi_{\mathrm{CH} 4}$ ) but also on methane sensitivity and on the pilot fuel stoichiometric AFR.

\section{Heat Release Rate (HRR)}

The HRR of dual-fuel combustion in RCEM (Figure 9) shows a distinct peak associated with combustion of the pilot fuel

FIGURE 9 Dependence of HRR on the methane charge equivalence ratio for POMDME (full line) and $n$-dodecane (dashed) pilot fuels. Injector ET $=500 \mu \mathrm{s}$.

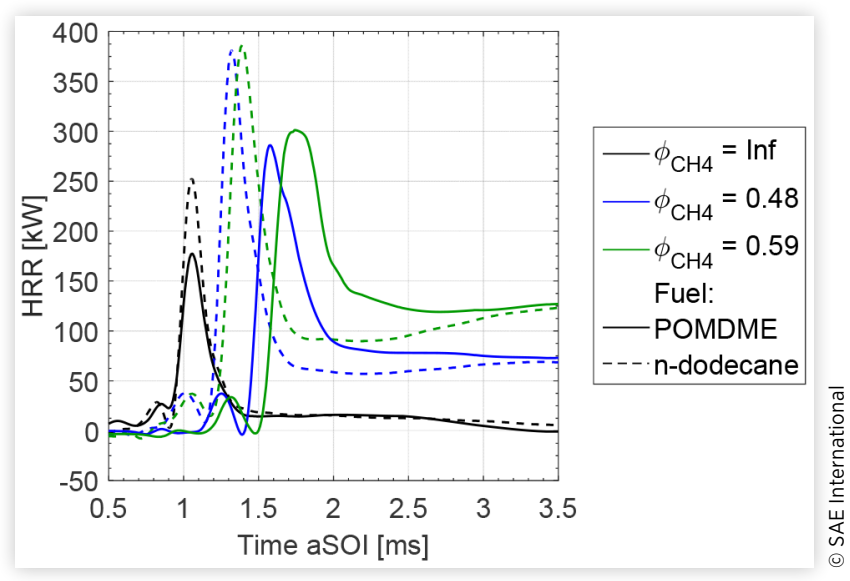

(c) 2018 SAE International. All Rights Reserved. 
and entrained methane, followed by a rather steady and slower burning of premixed methane mixture. The smaller peak prior to the main HRR coincides with softening of the Schlieren contours (not shown here) and has been therefore associated to the cool-flame combustion of pilot fuel [48]. Overall, this HRR shape is rather different than in typical Otto engines, as also expected considering the quiescent flow conditions in RCEM. Nevertheless, this makes it possible to study the combustion of the pilot fuel only, and the transition to premixed flame propagation, without this HRR phenomena being masked by the fast premixed flame propagation. The HRR level after the transition is expected to correlate well to the flame-kernel area initiated by the pilot-fuel combustion.

Figure 9 presents the HRR of POMDME and n-dodecane injections in air and in methane/air mixture with $\phi_{\mathrm{CH} 4}=0.59$. In air, with n-dodecane approximately $50 \%$ higher peak HRR than for the POMDME injection has been detected, at approximately constant combustion duration. Considering a factor 2 difference in the pilot injection LHV even higher difference in peak HRR would be expected. This is an indication that at least in the $n$-dodecane case oxygen appears to be the limiting reactant in the combustion.

In methane/air mixture due to the difference in ignition delay direct comparison of HRR between fuels is not possible. The difference in peak HRR between fuels decreases from $50 \%$ in air to about $30 \%$ in mixture with $\phi_{\mathrm{CH} 4}=0.59$. This effect is attributed to longer time available for mixing in combination with burning of the entrained methane. Duration of the peak HRR with POMDME is longer, indicating lower reactivity in the spray. Immediately after the peak, higher HRR values were observed with POMDME. However, by the time of $3.5 \mathrm{~ms}$ aSOI the HRR with both pilot-fuels reaches similar values indicating comparable area of the flame kernel initiated.

The influence of injection duration (ET) variation for POMDME fuel is shown in Figure 10. Regardless of similar ignition delay for all injection ETs, different shapes of the HRR have been measured. $400 \mu$ s and $500 \mu$ s ET injections show a characteristic premixed peak HRR and no distinguishable diffusion part. Contrary, the longest injection $(700 \mu \mathrm{s}$ ET) shows a considerable diffusion combustion part. The injection

\section{FIGURE 10 Comparison of the POMDME pilot fuel HRR in} air (full line) and methane/air charge (dashed, $\phi_{\mathrm{CH} 4}=0.48$ ) for a variation of POMDME injection ET.

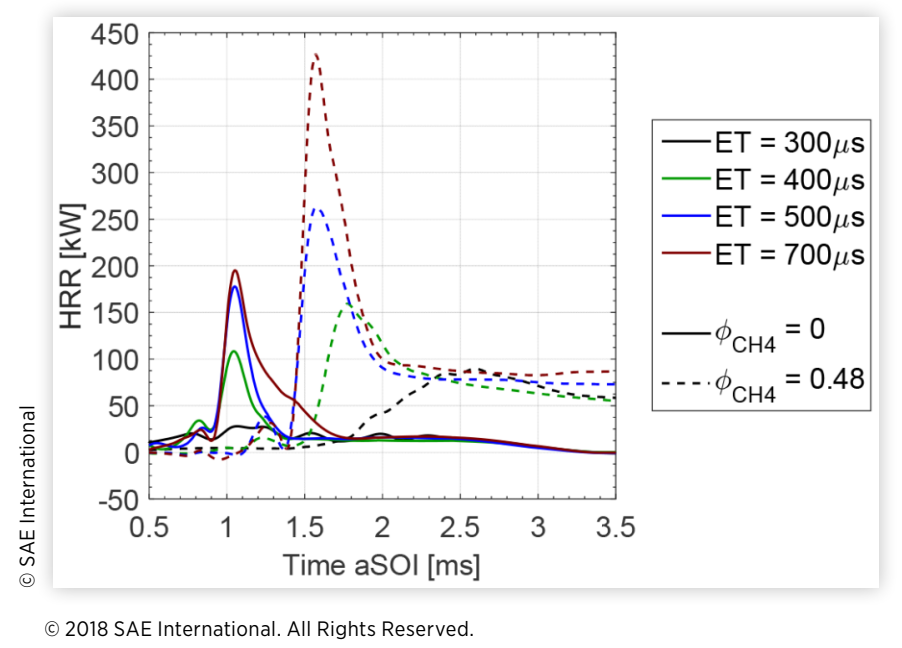

with $\mathrm{ET}=300 \mu$ s shows no clear peak in the HRR, indicating a lean-out for the short injection already in air.

In methane mixture considerable differences in the peak HRR are visible among different POMDME injections. $\mathrm{ET}=700 \mu$ s injection shows $70 \%$ higher peak HRR comparing to the $500 \mu$ s ET injection, despite only $30 \%$ increased pilot fuel mass and comparable spray penetration at the time of ignition (Figure 4). This is an indication for higher reactivity of a more fuel-rich mixture at the time of ignition, generated by a longer injection. Same observation can be made for the difference between the $400 \mu$ s and $500 \mu$ s ET injection. Additionally, the longer ignition delay of $400 \mu$ s ET injection is already the first indication of lean-out. The shortest $\mathrm{ET}=300 \mu$ s injection again shows considerable signs of leanout: very slow HRR rise and low peak as well as considerably delayed ignition. Contrary, for $n$-dodecane no such sign of lean-out has been detected even in the case of shortest ignition delay.

\section{Engine Results and Discussion}

The engine investigations were focused on the applicability of POMDME in realistic case in a dual-fuel engine. Commercial Diesel was used instead of dodecane as a reference fuel to simulate more realistic situation, since high cetane number HC fuels like dodecane are rarely used in engines. Nevertheless, the findings from RCEM test rig were used in this section to aid the interpretation of the engine results. In particular, we focus on the relative importance of the pilot fuel cetane number, and chemical influence of methane as well as the importance of the fuel reactivity and mixture state at ignition on the consequent HRR.

\section{Ignition Delay Analysis}

A variation in the global equivalence ratio with respect to the ignition delay was investigated in OP1 - OP3 (cf. Table 5). Each of the operating points was recorded with POMDME pilotfuel and repeated with Diesel as a reference. The comparison of ignition delays of OP1 - OP3 for both pilot fuels, presented as a function of the charge equivalence ratio, is shown in Figure 11. The global equivalence ratio of each operating point is varied and feedback controlled to $1,0.91,0.83$ and 0.78 . In comparison of the Diesel and the POMDME cases with same injection duration (OP2 and OP3) a small difference in the charge equivalence ratio originates from the different stoichiometric AFR of the two pilot fuels. The ignition delay was found increasing with increasing substrate- and also global equivalence ratios in all cases.

OP1 represents a low load condition with 5 bar BMEP at $1600 \mathrm{rpm}$. To assure stable operation in OP1 with the Diesel pilot-fuel an increased pilot-fuel quantity in comparison to the corresponding cases with POMDME was necessary. Therefore lower substrate equivalence ratio was used. The smallest pilot fuel quantity (highest substrate $\varphi$ ) in the Diesel OP1 operating conditions shows an ignition delay of 
FIGURE 11 Ignition delays for the global $\varphi$ variation for three operating points; OP1: 1600 rpm, 5 bar BMEP, 10 wt. \% EGR; OP2: 1600 rpm, 8 bar BMEP, 10 wt. \% EGR; OP3: 1600 rpm, 8 bar BMEP, 20 wt. \% EGR.

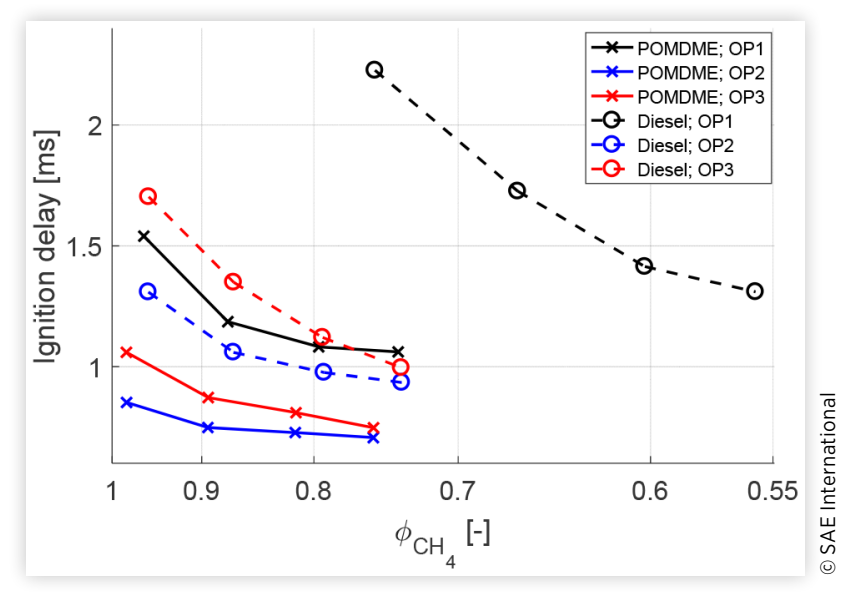

approximately $2.2 \mathrm{~ms}$ and a further reduction of the pilot fuel quantity leads to misfire. At medium load (8 bar BMEP at $1600 \mathrm{rpm}, \mathrm{OP} 2$ \& OP3) engine operation with comparable amount of pilot fuel both for the Diesel and the POMDME pilot-fuels was possible. This was attributed to the higher cylinder pressure at higher load reducing the ignition delay for both fuels. Influence of lower heat losses due to the higher cylinder wall temperature cannot be excluded as well. Moving from OP2 to OP3 higher EGR rate and the earlier injection timing resulted in prolonged ignition delay. Nevertheless, the engine operation was still feasible with both pilot fuels even at the shorter injection duration.

In contrary to RCEM tests (using dodecane as HC pilot fuel) in engine POMDME was found to be less prone to misfire than HC-based Diesel fuel. The main difference between the $\mathrm{HC}$ fuels in different test rigs is the cetane number (73 for dodecane vs. 52 for Diesel). Despite the higher sensitivity of POMDME to methane the large difference in cetane number appears to be the dominant influence governing successful ignition in Diesel cases. Nevertheless, even in the engine tests with POMDME the methane strongly influences the ignition and this influence has to be taken into account. The influence of the pilot fuel quantity and ignition delay on the engine performance in terms of HRR is presented in the following.

OP4 considers stoichiometric global equivalence ratio under varying pilot fuel quantities, recorded at $1600 \mathrm{rpm}$, 5 bar BMEP and $20 \mathrm{wt}$. \% EGR. Considering the methane deferring the ignition stoichiometric operating conditions are the most challenging to reliably ignite. Figure 12 illustrates the ignition delay as a function of the pilot fuel quantity. A reduction of the pilot fuel quantity increases the ignition delay for both fuels. For the Diesel case, a lower pilot fuel mass than $6.5 \mathrm{mg}$ could not be applied due to the overmixing induced misfire. Similar to OP1, stable engine operation with POMDME could be achieved at lower pilot-fuel mass. The smallest considered pilot fuel quantity of POMDME (2.8 mg/ cyl) still leads to a shorter ignition delay than the highest of Diesel (9 mg/cyl).
FIGURE 12 Ignition delay as function of the injected pilotfuel mass for Diesel and for POMDME cases of OP4; 1600 rpm, 5 bar BMEP, 20 wt. \% EGR and global $\varphi=1$.

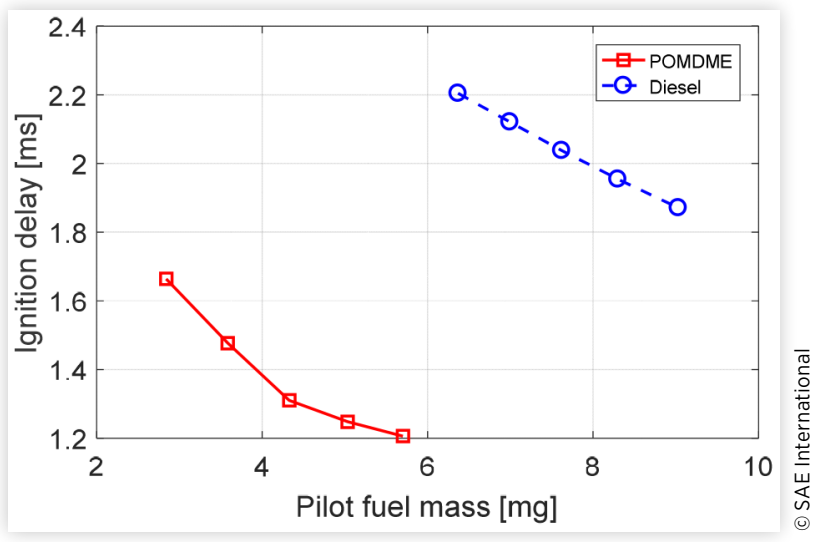

It has to be emphasized that controlling the global equivalence ratio at increasing pilot-fuel quantity reduces the substrate-fuel equivalence ratio. For example, the substratefuel equivalence ratio is 0.56 for the larges Diesel quantity (9 $\mathrm{mg} / \mathrm{cyl})$ and 0.7 for the smallest quantity $(6.4 \mathrm{mg} / \mathrm{cyl})$. Analogously for the POMDME cases the values vary between 0.88 for the largest quantity $(5.7 \mathrm{mg} / \mathrm{cyl})$ and 0.94 for the smallest one $(2.8 \mathrm{mg} / \mathrm{cyl})$. Both the fuel-share as well as the end-of-injection transients (according to Figure 7) affect the ignition delay. Therefore solely the influence of the pilot fuel quantity cannot be isolated from this information. Furthermore, changes in substrate equivalence ratio also influence the specific heat ratio of the charge and therefore to a small extent $(\sim 10 \mathrm{~K})$ affect the compression temperature.

\section{Engine HRR Analysis}

In the RCEM strongly reduced peak HRR and slow combustion of the pilot-fuel was observed close to lean-out. Significantly longer time elapsed between the ignition and established flame propagation. In the long injection cases away from lean-out POMDME was found to be slightly less reactive than $\mathrm{n}$-dodecane leading to slower pilot-fuel combustion. This section investigates the consequences of lower fuel reactivity close to lean-out of the HRR in the engine environment.

The heat release rates for the POMDME cases of OP4 are displayed in Figure 13. The five curves represent the different amounts of pilot injection fuel. As the pilot injection mass is augmented, shortened ignition delay and higher peak HRR is detected. Higher pilot quantity, respectively shorter ignition delay leads to a reduced combustion duration. The first minor increase in the heat release rates (between -5 and $-2{ }^{\circ}$ ATDC) is assumed to be the low temperature combustion (LTC), as already observed in the RCEM (Figure 9). No clear correlation between the pilot-fuel mass (ignition delay) and the timing or the peak HRR of LTC has been observed.

Figure 14 shows the heat release rates of OP4 using Diesel as a pilot fuel. Similar to POMDME, the higher pilot fuel quantity leads to shorter combustion duration. More prominent peak of the LTC HRR is observed, with larger temporal separation of the LTC and ignition. Regardless of the lower 
FIGURE 13 Heat release rates for POMDME as pilot fuel with different pilot injection quantities; OP4: 1600 rpm, 5 bar BMEP, 20 wt. \% EGR and global $\varphi=1$.

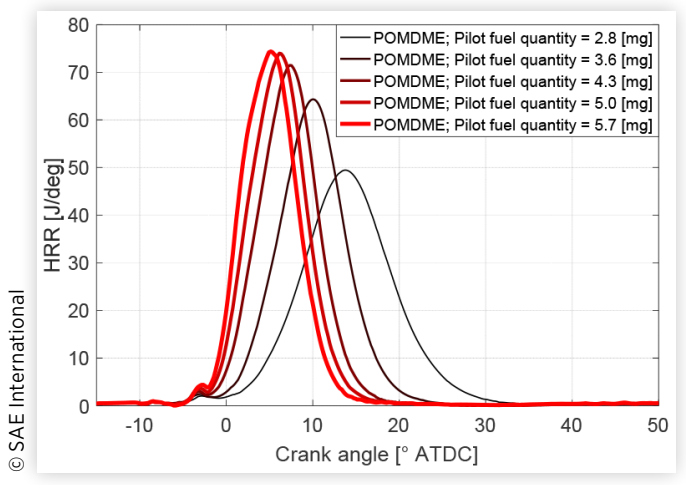

FIGURE 14 Heat release rates for Diesel as pilot fuel with different pilot injection quantities; OP4: 1600 rpm, 5 bar BMEP, 20 wt. $\%$ EGR and global $\varphi=1$.

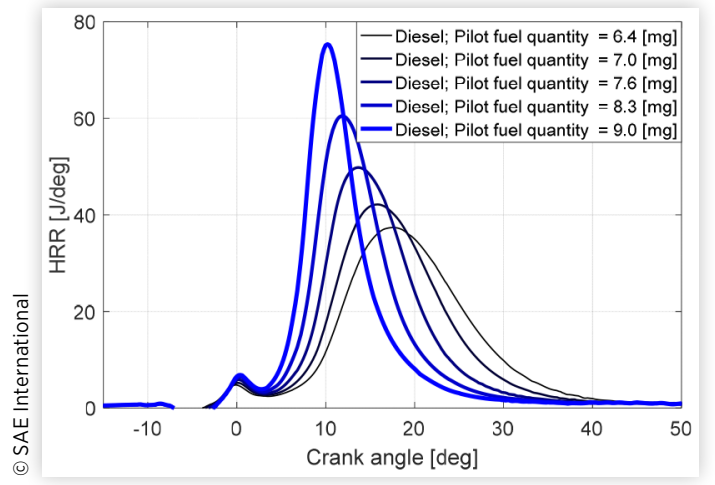

range of pilot-fuel mass in comparison with POMDME cases, a larger difference between the highest and the lowest peak HRR has been detected. This result is attributed to the changes in fuel composition, which is different for each combination of pilot and substrate fuel ratio. In addition, the endotherm phase after injection appears also more prominent in the case of Diesel pilot fuel. This behavior most possibly originates from the difference in latent heat of vaporization. However, the quantitative values for the used POMDME blends are unknown. A higher latent heat of vaporization would cause a prolongation of the ignition delay due to the local temperature reduction.

A comparison of the heat release rates with POMDME and Diesel pilot-fuel is shown in Figure 15 (OP4). The POMDME case with smallest pilot quantity is shown alongside to the Diesel pilot-fuel case with the HRR best matching this POMDME case (i.e. the intermediate pilot fuel quantity with $7.6 \mathrm{mg}$ ). This comparison demonstrates the possibility of a reduction of pilot fuel consumption using POMDME instead of the Diesel pilot fuel. For these operating conditions at same combustion phasing the pilot-fuel energy share could be reduced to $7 \%$ with POMDME in comparison to $37 \%$ with Diesel fuel. In general, significantly lower pilot-fuel energetic input was necessary to achieve the same combustion phasing as with the Diesel pilot-fuel.
FIGURE 15 Heat release rate the POMDME case with the smallest pilot quantity (red) compared to a case with Dieselfuel and comparable combustion phasing (blue); OP4: 1600 rpm, 5 bar BMEP, 20 wt. \% EGR and global $\varphi=1$.

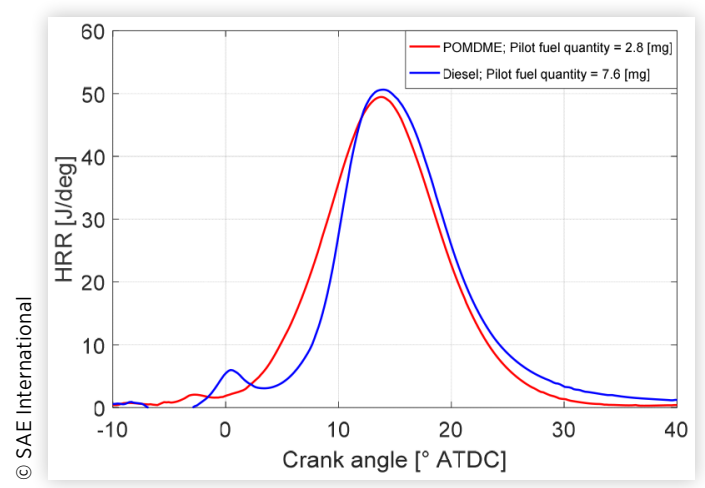

Besides the ignition delay also the size of initiated ignition kernel, ignition location, pilot fuel stoichiometric AFR, the injection-generated turbulence, the charge equivalence ratio and the unburnt temperature (changing with combustion phasing) are expected to govern the HRR. Overall, the HRR analysis shows that the pilot-fuel ignition delay controls the combustion phasing within this operating range. The generally faster combustion in the POMDME cases in comparison to the diesel cases is attributed to the smaller ignition delay due to the higher cetane number and the higher background equivalence ratio (the global equivalence ratio is constant). In contrary to the RCEM HRR analysis, a longer ignition delay does not promote the HRR due to a larger ignition area (spray volume) - the reactivity in this area is lower due to longer mixing, and the temperature is lower due to expansion. Summarized, the combustion duration shows a high sensitivity on the ignition delay. The optimum ignition delay is complex to determine, since it is depending on the numerous above-mentioned factors. The difference in ignition delay itself is depending on the cetane number, the methane sensitivity and the stoichiometric AFR of the pilot fuel. The results of OP4 imply that a further reduction of the ignition delay could increase the combustion efficiency. Disregarding the effects on the emissions, this reduction could be achieved with a pilot fuel with less methane sensitivity and a higher stoichiometric AFR like dodecane, as shown in the RCEM experiments.

\section{Engine Soot Emissions}

To demonstrate the additional advantage of POMDME, the operating conditions OP5-OP8 are recorded in a region of the engine map with typically high soot emissions. Similar to the previous cases, these operating points were recorded with POMDME and Diesel pilot fuel in order to compare the emissions characteristics of both fuels. The duration of injection for the two fuels are equal in these operating conditions. This has the consequence, that the substrate equivalence ratio is minorly higher for the cases with POMDME due to the lower stoichiometric AFR of POMDME. The operating conditions were recorded with particularly high EGR rate at 4 bar BMEP and stoichiometric global $\varphi$ (as also shown in Table 5): 
- OP 5: $1500 \mathrm{rpm}, 35 \%$ EGR, swirl flap closed, DOI $570 \mu \mathrm{s}$

- OP 6: $1500 \mathrm{rpm}, 35 \%$ EGR, swirl flap open, DOI $570 \mu \mathrm{s}$

- OP 7: $2000 \mathrm{rpm}, 40 \%$ EGR, swirl flap open, DOI $600 \mu \mathrm{s}$

- OP 8: 2000 rpm, 40\% EGR, swirl flap open, DOI $700 \mu \mathrm{s}$

The particulate matter emissions for the four different operating points are shown in Figure 16. The blue bars represent the cases with Diesel as pilot fuel and the red ones represent the cases with POMDME. In OP5, the PM emissions are more than 200 times higher with Diesel compared to POMDME. Interestingly, the PM emissions of both pilot fuels in OP5 are higher than with the corresponding pilot fuel in OP6, which is a similar operating condition but with open swirl valve. The reason is assumed in a higher soot formation rate due to faster combustion leading to higher temperatures and generally very low soot oxidation rate due to globally stoichiometric combustion. However, the conclusion, that more swirl increases PM cannot be made in general. For operating points 6-8, with POMDME as pilot fuel the recorded soot mass is below the detection limit. In contrary, high soot emissions were detected also for OP6 - OP8 with Diesel as pilot fuel. This massive reduction of soot emissions with POMDME was attributed to the high degree of oxygenation of POMDME (47 wt. \% of oxygen). First, the oxygen content directly reduces the soot formation, second, the lower stoichiometric AFR reduces fuel rich areas in the pilot fuel spray and third, absence of aromatic compounds and $\mathrm{C}-\mathrm{C}$ bonds in POMDME reduces the availability of soot precursors.

The spectral distribution of soot particulate size for these four operating points is illustrated in Figure 17. The blue lines illustrate the operating points with Diesel as pilot fuel and the red lines the cases with POMDME as pilot fuel. For the Diesel cases a higher soot particle number can be seen compared to POMDME. The soot size spectral distribution for the Diesel case represents particles in the agglomeration mode with a count median diameter between 84 and $119 \mathrm{~nm}$. Substitution of Diesel with POMDME leads to a lower soot particle number and to a lower soot size. For operating condition OP5, with

FIGURE 16 Particulate matter emissions for 4 different operating points with POMDME and Diesel as pilot fuel; OP 5: 1500 rpm, 4 bar BMEP, 35\% EGR, Swirl closed; OP 6: 1500 rpm, 4 bar BMEP, 35\% EGR, Swirl closed; OP 7: 2000 rpm, 4 bar BMEP, 40\% EGR, Swirl open, DOI $600 \mu \mathrm{s}$; OP 8: 2000 rpm, 4 bar BMEP, 40\% EGR, Swirl open, DOI $700 \mu \mathrm{s}$.

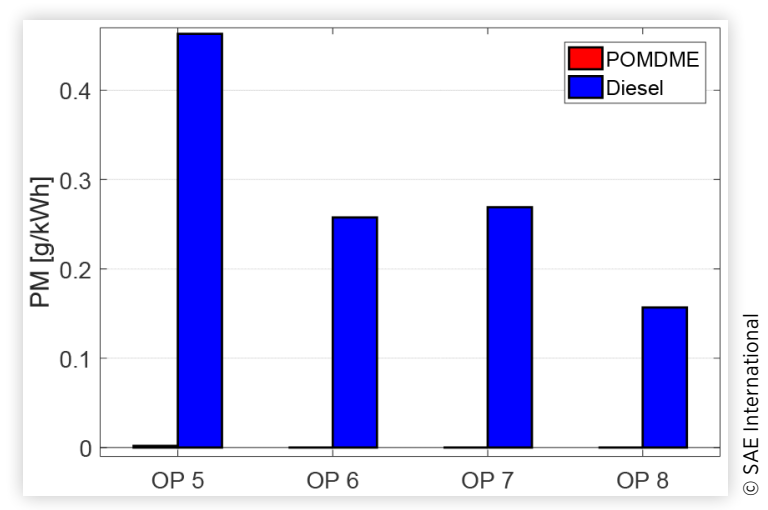

FIGURE 17 Particle-size spectral distribution for 4 different operating points with POMDME and Diesel as pilot fuel; OP 5: 1500 rpm, 4 bar BMEP, 35\% EGR, Swirl closed; OP 6: 1500 rpm, 4 bar BMEP, 35\% EGR, Swirl closed; OP 7: 2000 rpm, 4 bar BMEP, 40\% EGR, Swirl open, DOI $600 \mu \mathrm{s}$; OP 8: 2000 rpm, 4 bar BMEP, 40\% EGR, Swirl open, DOI $700 \mu \mathrm{s}$.

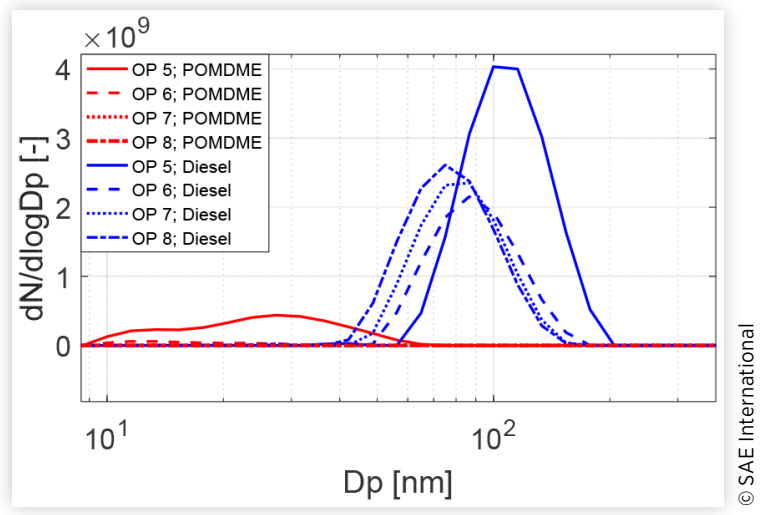

POMDME, the count median diameter is around $30 \mathrm{~nm}$. Since no clear agglomeration mode is visible, the primary particle size cannot be estimated. This particle size corresponds to the nucleation mode and due to the only small-chain fuel compounds (no long compounds expected from POMDME and $\mathrm{CNG}$ ), the particles are expected to be of solid composition, even in case of the smallest particles. The contribution of lube oil is unknown. OP7 and OP8 do not show particle number concentration above the signal noise in any size range.

\section{Summary and Conclusions}

The applicability of POMDME as an alternative pilot fuel for dual-fuel gas engines has been experimentally investigated in a RCEM and automotive-size dual-fuel adapted VW Diesel engine.

In the RCEM, a single-hole Diesel injector has been used to admit the pilot fuel (POMDME or n-dodecane as a reference) into different premixed compressed mixtures of methane and air. To provide the reference cases injections into air have been performed as well. $\mathrm{OH}^{*}$ chemiluminescence and Schlieren imaging have been employed to extract combustion relevant metrics like the pilot spray penetration and the ignition delay. Optical investigations were substantiated by the HRR analysis.

A modified VW industrial engine has been used to compare POMDME and Diesel as pilot fuels in dual fuel operation. Three different sets of operating conditions have been carried out, with focus on the variation of the global equivalence ratio, the pilot fuel quantity (resp. the charge equivalence ratio) and operating condition with high soot formation potential.

Based on the analysis of experimental results, following conclusions can be stated:

1. No difference in spray evolution of POMDME and $\mathrm{n}$-dodecane prior to the ignition has been detected. As expected based on existing empirical correlations, 
the difference in pilot-fuel density has small influence on the pilot spray evolution. This confirms that the same spray mixture distribution can be assumed for both fuels.

2. POMDME and n-dodecane have similar cetane numbers, leading to similar ignition delay of both fuels in air. POMDME was found to exhibit a 7\% longer ignition delay than $\mathrm{n}$-dodecane. Ignition delays of both fuels were found sensitive to the concentration of premixed methane. At methane $\phi_{\mathrm{CH} 4}=0.59$, up to $100 \%$ increased ignition delay has been detected for POMDME. The sensitivity of POMDME ignition delay to methane is about $70 \%$ higher than the sensitivity of $n$-dodecane.

3. In the RCEM, HRR analysis and ignition delay detection indicated overmixing of the shorter POMDME injections in dual-fuel operation, leading to a slow rise of HRR and prolonged ignition delay in comparison to longer injections. Contrary, in the dual-fuel engine operated with POMDME and EN590 Diesel pilot fuels, POMDME was found to have a lower sensitivity of the ignition delay to methane and lower tendency to overmixing and misfire. Ignition delays in dual-fuel operation were up to $50 \%$ lower when using POMDME pilot fuel comparing to Diesel pilot-fuel.

4. The tendency of pilot-fuels to overmixing and misfire has been explained by a conceptual model considering 1D spray model results, pilot-fuel ignition delay in air (cetane number) and sensitivity of fuels to methane concentration. Cetane number of pilot-fuel and ignition delay sensitivity in regard to methane were shown to together determine the minimal necessary pilot-fuel quantity. Overall, the results suggest higher importance of the pilot-fuel cetane number than the sensitivity to methane.

5. Engine operation with POMDME was possible with considerably lower pilot-fuel mass and energy input comparing to operation with Diesel pilot-fuel. Even under the least reactive conditions no misfire occurred in POMDME pilot-fuel operation. This advantage of POMDME was attributed to its high cetane number.

6. Combustion phasing was strongly dependent on the pilot-fuel quantity. Faster combustion was detected for higher pilot-fuel portions. When the engine was operated with POMDME instead of Diesel pilot fuel, combustion phasing control was possible with considerably decreased pilot-fuel amount. This was attributed to lower POMDME misfire tendency, attributed to the higher POMDME cetane number.

7. The engine raw soot emissions (after turbine) with POMDME were at least two orders of magnitude lower than when the engine was operated with Diesel pilot fuel at the same injection duration. This was attributed to the high level of POMDME oxygenation and higher stoichiometric AFR.

Corroborating all experimental results from the RCEM and dual-fuel engine, large potential of POMDME as an alternative pilot fuel for dual-fuel engines has been demonstrated.
High cetane number of POMDME enables combustion phasing control at considerably reduced pilot-fuel consumption and virtually smokeless operation. For optimal engine control, when using different pilot fuels, both the cetane number difference as well as the difference in pilot-fuel ignition delay sensitivity to methane has to be accounted.

Suggestions for future work include engine tests using a HC fuel with high cetane number (comparable to POMDME). This would give additional confidence in the conclusion claiming that the cetane number of pilot-fuel is the most important parameter influencing the combustion phasing.

\section{References}

1. Wei, L. and Geng, P., “A Review on Natural Gas/Diesel Dual Fuel Combustion, Emissions and Performance," Fuel Processing Technology 142(Supplement C):264-278, 2016, doi:10.1016/j.fuproc.2015.09.018.

2. Thomson, H., Corbett, J.J., and Winebrake, J.J., "Natural Gas as a Marine Fuel," Energy Policy 87:153-167, 2015, doi:10.1016/j.enpol.2015.08.027.

3. Krishnan, S.R., Srinivasan, K.K., Singh, S., Bell, S.R. et al., "Strategies for Reduced Nox Emissions in Pilot-Ignited Natural Gas Engines," Journal of Engineering for Gas Turbines and Power 126(3):665-671, 2004, doi:10.1115/1.1760530.

4. Zhang, Y., Ghandhi, J., and Rothamer, D., "Effects of Fuel Chemistry and Spray Properties on Particulate Size Distributions from Dual-Fuel Combustion Strategies," $S A E$ Int. J. Engines 10(4):1847-1858, 2017, doi:10.4271/2017-01-1005.

5. Rochussen, J., Yeo, J., and Kirchen, P., "Effect of Fueling Control Parameters on Combustion and Emissions Characteristics of Diesel-Ignited Methane Dual-Fuel Combustion," SAE Technical Paper 2016-01-0792, 2016, doi:10.4271/2016-01-0792.

6. Abd Alla, G.H., Soliman, H.A., Badr, O.A., and Abd Rabbo, M.F., "Effect of Pilot Fuel Quantity on the Performance of a Dual Fuel Engine," Energy Conversion and Management 41(6):559-572, 2000, doi:10.1016/S0196-8904(99)00124-7.

7. Zhou, L., Liu, Y.-F., Wu, C.-B., Sun, L. et al., "Effect of the Diesel Injection Timing and the Pilot Quantity on the Combustion Characteristics and the Fine-Particle Emissions in a Micro-Diesel Pilot-Ignited Natural-Gas Engine," Proceedings of the Institution of Mechanical Engineers, Part D: Journal of Automobile Engineering 227(8):1142-1152, 2013, doi:10.1177/0954407013480452.

8. Liu, J., Yang, F., Wang, H., Ouyang, M. et al., "Effects of Pilot Fuel Quantity on the Emissions Characteristics of a Cng/ Diesel Dual Fuel Engine with Optimized Pilot Injection Timing," Applied Energy 110(Supplement C):201-206, 2013, doi:10.1016/j.apenergy.2013.03.024.

9. Magno, A., Mancaruso, E., and Vaglieco, B.M., "Combustion Analysis of Dual Fuel Operation in Single Cylinder Research Engine Fuelled with Methane and Diesel," SAE Technical Paper 2015-24-2461, 2015, doi:10.4271/2015-24-2461.

10. Pettinen, R., Kaario, O., and Larmi, M., "Dual-Fuel Combustion Characterization on Lean Conditions and High 
Loads," SAE Technical Paper 2017-01-0759, 2017, doi:10.4271/2017-01-0759.

11. Dronniou, N., Kashdan, J., Lecointe, B., Sauve, K. et al., "Optical Investigation of Dual-Fuel Cng/Diesel Combustion Strategies to Reduce $\mathrm{Co}_{2}$ Emissions," SAE Int. J. Engines 7:873-887, 2014, doi:10.4271/2014-01-1313.

12. Nithyanandan, K., Gao, Y., Wu, H., Lee, C.-F. et al., "An Optical Investigation of Multiple Diesel Injections in Cng/ Diesel Dual-Fuel Combustion in a Light Duty Optical Diesel Engine," SAE Technical Paper 2017-01-0755, 2017, doi:10.4271/2017-01-0755.

13. Ahmad, Z., Aryal, J., Ranta, O., Kaario, O. et al., "An Optical Characterization of Dual-Fuel Combustion in a Heavy-Duty Diesel Engine," SAE Technical Paper 2018-01-0252, 2018, doi:10.4271/2018-01-0252.

14. Schlatter, S., Schneider, B., Wright, Y., and Boulouchos, K., "Experimental Study of Ignition and Combustion Characteristics of a Diesel Pilot Spray in a Lean Premixed Methane/Air Charge Using a Rapid Compression Expansion Machine," SAE Technical Paper 2012-01-0825, 2012, doi:10.4271/2012-01-0825.

15. Schlatter, S., Schneider, B., Wright, Y.M., and Boulouchos, K., "N-Heptane Micro Pilot Assisted Methane Combustion in a Rapid Compression Expansion Machine," Fuel 179:339352, 2016, doi:10.1016/j.fuel.2016.03.006.

16. Srna, A., Bruneaux, G., von Rotz, B., Bombach, R. et al., "Optical Investigation of Sooting Propensity of N-Dodecane Pilot/Lean-Premixed Methane Dual-Fuel Combustion in a Rapid Compression-Expansion Machine," SAE Technical Paper 2018-01-0258, 2018, doi:10.4271/2018-01-0258.

17. Salaun, E., Apeloig, J., Grisch, F., Yvonnet, C.-E. et al., “Optical Investigation of Ignition Timing and Equivalence Ratio in Dual-Fuel CNG/Diesel Combustion," SAE Technical Paper 2016-01-0772, 2016, doi:10.4271/2016-01-0772.

18. Kikusato, A., Fukasawa, H., Nomura, K., Kusaka, J. et al., “A Study on the Characteristics of Natural Gas Combustion at a High Compression Ratio by Using a Rapid Compression and Expansion Machine," SAE Technical Paper 2012-01-1651, 2012, doi:10.4271/2012-01-1651.

19. Saito, H., Sakurai, T., Sakonji, T., Hirashima, T. et al., "Study on Lean Burn Gas Engine Using Pilot Oil as the Ignition Source," SAE Technical Paper 2001-01-0143, 2001, doi:10.4271/2001-01-0143.

20. Papagiannakis, R.G. and Hountalas, D.T., "Combustion and Exhaust Emission Characteristics of a Dual Fuel Compression Ignition Engine Operated with Pilot Diesel Fuel and Natural Gas," Energy Conversion and Management 45(18):2971-2987, 2004, doi:10.1016/j.enconman.2004.01.013.

21. Lounici, M.S., Loubar, K., Tarabet, L., Balistrou, M. et al., "Towards Improvement of Natural Gas-Diesel Dual Fuel Mode: An Experimental Investigation on Performance and Exhaust Emissions," Energy 64(Supplement C):200-211, 2014, doi:10.1016/j.energy.2013.10.091.

22. Srna, A., Bolla, M., Wright, Y.M., Herrmann, K. et al., "Effect of Methane on Pilot-Fuel Auto-Ignition in Dual-Fuel Engines," Proceedings of the Combustion Institute 37, 2018, doi:10.1016/j.proci.2018.06.177.

23. Idicheria, C.A. and Pickett, L.M., "Ignition, Soot Formation, and End-of-Combustion Transients in Diesel Combustion under High-EGR Conditions," International Journal of Engine Research 12(4):376-392, 2011, doi: $10.1177 / 1468087411399505$.

24. Malbec, L.-M., Eagle, W.E., Musculus, M.P.B., and Schihl, P., "Influence of Injection Duration and Ambient Temperature on the Ignition Delay in a 2.34L Optical Diesel Engine," SAE Int. J. Engines 9(1):47-70, 2016, doi:10.4271/2015-01-1830.

25. Miles, P.C., Sahoo, D., Busch, S., Trost, J. et al., "Pilot Injection Ignition Properties under Low-Temperature, Dilute In-Cylinder Conditions," SAE Int. J. Engines 6(4):1888-1907, 2013, doi:10.4271/2013-01-2531.

26. Musculus, M.P.B., Lachaux, T., Pickett, L.M., and Idicheria, C.A., "End-of-Injection over-Mixing and Unburned Hydrocarbon Emissions in Low-Temperature-Combustion Diesel Engines," SAE Technical Paper 2007-01-0907, 2007, doi:10.4271/2007-01-0907.

27. Barro, C., Nani, C., Hutter, R., and Boulouchos, K., "Spray Model Based Phenomenological Combustion Description and Experimental Validation for a Dual Fuel Engine," SAE Technical Paper 2017-24-0098, 2017, doi:10.4271/2017-24-0098.

28. Barro, C., Lucjan, A., Li, Z., Kyrtatos, P. et al., "Development and Experimental Validation of a Fast Spray Ignition Model for Diesel Engines Using Insights from CFD Spray Calculations," SAE Int. J. Fuels Lubr. 10(2):304-317, 2017, doi:10.4271/2017-01-0812.

29. Merola, S.S., Tornatore, C., Iannuzzi, S.E., Marchitto, L. et al., "Combustion Process Investigation in a High Speed Diesel Engine Fuelled with N-Butanol Diesel Blend by Conventional Methods and Optical Diagnostics," Renewable Energy 64:225-237, 2014, doi:10.1016/j.renene.2013.11.017.

30. Zhu, L., Cheung, C.S., Zhang, W.G., and Huang, Z., "Influence of Methanol-Biodiesel Blends on the Particulate Emissions of a Direct Injection Diesel Engine," Aerosol Science and Technology 44(5):362-369, 2010, doi: $10.1080 / 02786821003652646$.

31. Manin, J., Skeen, S., Pickett, L., Kurtz, E. et al., "Effects of Oxygenated Fuels on Combustion and Soot Formation/ Oxidation Processes," SAE Int. J. Fuels Lubr. 7(3):704-717, 2014, doi:10.4271/2014-01-2657.

32. Härtl, M., Seidenspinner, P., Jacob, E., and Wachtmeister, G., "Oxygenate Screening on a Heavy-Duty Diesel Engine and Emission Characteristics of Highly Oxygenated Oxymethylene Ether Fuel Ome1," Fuel 153(Supplement C):328-335, 2015, doi:10.1016/j.fuel.2015.03.012.

33. Iannuzzi, S.E., Barro, C., Boulouchos, K., and Burger, J., "Combustion Behavior and Soot Formation/Oxidation of Oxygenated Fuels in a Cylindrical Constant Volume Chamber," Fuel 167(Supplement C):49-59, 2016, doi:10.1016/j. fuel.2015.11.060.

34. Iannuzzi, S.E., Barro, C., Boulouchos, K., and Burger, J., "Pomdme-Diesel Blends: Evaluation of Performance and Exhaust Emissions in a Single Cylinder Heavy-Duty Diesel Engine," Fuel 203(Supplement C):57-67, 2017, doi:10.1016/j. fuel.2017.04.089.

35. Pellegrini, L., Marchionna, M., Patrini, R., and Florio, S., "Emission Performance of Neat and Blended Polyoxymethylene Dimethyl Ethers in an Old Light-Duty Diesel Car," SAE Technical Paper 2013-01-1035, 2013, doi:10.4271/2013-01-1035. 
36. Teng, H. and McCandless, J.C., "Can Heavy-Duty Diesel Engines Fueled with DME Meet US 2007/2010 Emissions Standard with a Simplified Aftertreatment System," SAE Technical Paper 2006-01-0053, 2006, doi:10.4271/2006-01-0053.

37. Oguma, M. and Goto, S., "Evaluation of Medium Duty DME Truck Performance-Field Test Results and PM Characteristics," SAE Technical Paper 2007-01-0032, 2007, doi:10.4271/2007-01-0032.

38. Bailey, B., Eberhardt, J., Goguen, S., and Erwin, J., "Diethyl Ether (DEE) as a Renewable Diesel Fuel," SAE Technical Paper 972978, 1997, doi:10.4271/972978.

39. Sivasankaralingam, V., Raman, V., Mubarak Ali, M.J., Alfazazi, A. et al., "Experimental and Numerical Investigation of Ethanol/Diethyl Ether Mixtures in a CI Engine," SAE Technical Paper 2016-01-2180, 2016, doi:10.4271/2016-01-2180.

40. Imran, S., Emberson, D.R., Diez, A., Wen, D.S. et al., "Natural Gas Fueled Compression Ignition Engine Performance and Emissions Maps with Diesel and RME Pilot Fuels," Applied Energy 124:354-365, 2014, doi:10.1016/j. apenergy.2014.02.067.

41. Song, H., Liu, C., Li, F., Wang, Z. et al., "A Comparative Study of Using Diesel and Poden as Pilot Fuels for Natural Gas Dual-Fuel Combustion," Fuel 188:418-426, 2017, doi:10.1016/j.fuel.2016.10.051.

42. Münz, M., Feiling, A., Beidl, C., Härtl, M. et al., "Oxymethylene Ether (OME1) as a Synthetic Low-Emission Fuel for Di Diesel Engines," in Internationaler Motorenkongress 2016: Mit Konferenz NfzMotorentechnologie, Liebl, J. and Beidl, C., Eds., (Wiesbaden: Springer Fachmedien Wiesbaden, 2016), 537-553.

43. Ogawa, H., Nabi, N., Minami, M., Miyamoto, N. et al., "Ultra Low Emissions and High Performance Diesel Combustion with a Combination of High EGR, Three-Way Catalyst, and a Highly Oxygenated Fuel, Dimethoxy Methane (DMM)," SAE Technical Paper 2000-01-1819, 2000, doi:10.4271/200001-1819.

44. Härtl, M., Gaukel, K., Pélerin, D., and Wachtmeister, G., "Oxymethylenether Als Potenziell Co2-Neutraler Kraftstoff Für Saubere Dieselmotoren Teil 1: Motorenuntersuchungen," MTZ - Motortechnische Zeitschrift 78(2):52-59, 2017, doi:10.1007/s35146-016-0170-9.

45. Burger, J., Siegert, M., Ströfer, E., and Hasse, H., "Poly(Oxymethylene) Dimethyl Ethers as Components of Tailored Diesel Fuel: Properties, Synthesis and Purification Concepts," Fuel 89(11):3315-3319, 2010, doi:10.1016/j. fuel.2010.05.014.

46. Schlatter, S., Schneider, B., Wright, Y.M., and Boulouchos, K., "Comparative Study of Ignition Systems for Lean Burn Gas Engines in an Optically Accessible Rapid Compression Expansion Machine," SAE Technical Paper 2013-24-0112, 2013, doi:10.4271/2013-24-0112.

47. Kammermann, T., Koch, J., Wright, Y.M., Soltic, P. et al., "Generation of Turbulence in a RCEM towards Engine Relevant Conditions for Premixed Combustion Based on CFD and PIV Investigations," SAE Int. J. Engines 10(4), 2017, doi:10.4271/2017-24-0043.

48. Skeen, S.A., Manin, J., and Pickett, L.M., "Simultaneous Formaldehyde PLIF and High-Speed Schlieren Imaging for
Ignition Visualization in High-Pressure Spray Flames," Proceedings of the Combustion Institute 35:3167-3174, 2015, doi:10.1016/j.proci.2014.06.040.

49. Bardi, M., Payri, R., Malbec, L.M.C., Bruneaux, G. et al., "Engine Combustion Network: Comparison of Spray Development, Vaporization, and Combustion in Different Combustion Vessels," 22(10):807-842, 2012, doi:10.1615/ AtomizSpr.2013005837.

50. Ott, T., Onder, C., and Guzzella, L., "Hybrid-Electric Vehicle with Natural Gas-Diesel Engine," Energies 6(7):3571-3592, 2013, doi:10.3390/en6073571.

51. Ott, T., Zurbriggen, F., Onder, C., and Guzzella, L., "Cylinder Individual Feedback Control of Combustion in a Dual Fuel Engine," IFAC Proceedings Volumes 46(21):600-605, 2013.

52. Zurbriggen, F., Hutter, R., and Onder, C., "Diesel-Minimal Combustion Control of a Natural Gas-Diesel Engine," Energies 9(1):58, 2016, doi:10.3390/en9010058.

53. Pickett, L.M., "Engine Combustion Network," http://www. sandia.gov/ecn/dieselSprayCombustion.php, 2013.

54. Musculus, M.P. and Kattke, K., "Entrainment Waves in Diesel Jets," SAE Int. J. Engines 2:1170-1193, 2009, doi:10.4271/2009-01-1355.

55. Naber, J.D. and Siebers, D.L., "Effects of Gas Density and Vaporization on Penetration and Dispersion of Diesel Sprays," SAE Technical Paper 960034, 1996, doi: $10.4271 / 960034$.

\section{Contact Information}

\author{
Aleš Srna \\ Paul Scherrer Institute \\ OVGA 119/A \\ CH-5232 Villigen PSI \\ Switzerland \\ ales.srna@psi.ch
}

\section{Acknowledgments}

Financial support from CCEM (project \#803: ScheDual), Research Association for Combustion Engines (FVV) and Swiss Federal Office of Energy (contract SI/501123-01 and $\mathrm{Sl} / 501020-01)$ is gratefully acknowledged.

\section{Definitions/Abbreviations}
AFR - Air-to-Fuel Ratio
BDC - Bottom Dead Center
BMEP - Brake-Mean Effective Pressure
CNG - Compressed Natural Gas
CR - Compression Ratio
DOI - Duration of Injection
DPF - Diesel Particulate Filter
EGR - Exhaust Gas Recirculation
ET - Injector Energizing Time
LHV - Lower Heating Value 
$\mathrm{NO}_{\mathbf{x}}$ - Nitrogen oxides

$\mathbf{O H}^{*}$ - Chemiluminescence of hydroxyl radical

OP - Operating Point

$\phi$ - Fuel/air equivalence ratio

$\phi_{\mathrm{CH} 4}$ - Methane/air equivalence ratio

PIV - Particle Image Velocimetry

PM - Particulate Matter
POMDME (PODE) (OME) - PolyOxyMethyleneDiMethylEther

RCEM - Rapid Compression-Expansion Machine

SOI - Start of Injection

TDC - Top Dead Center

$\mathbf{T}_{\text {sol }}$ - Temperature at the Start Of Injection

UHC - Unburnt Hydrocarbons

VTG - Variable Turbine Geometry

All rights reserved. No part of this publication may be reproduced, stored in a retrieval system, or transmitted, in any form or by any means, electronic, mechanical, photocopying, recording, or otherwise, without the prior written permission of the copyright holder.

Positions and opinions advanced in this paper are those of the author(s) and not necessarily those of SAE International. The author is solely responsible for the content of the paper.

ISSN 0148-7191 